\title{
INFLUÊNCIA DO PENSAMENTO DE LÍNGUA FRANCESA NA ACADEMIA BRASILEIRA DE ADMINISTRAÇÃO: UM OLHAR FRANCO-QUEBEQUENSE
}

\author{
L'influence de la pensée de langue française dans le champ des sciences administratives brésiliennes: \\ Un regard Franco-Québécois
}

The influence of French language thought on the Brazilian Administrative Sciences: A Quebec French look

Jean-François Chanlat 1,2,3 | jean-francois.chanlat@dauphine.psl.eu | ORCID : 0000-0003-1878-4707

${ }^{1}$ Universidade Paris-Dauphine PSL, Dauphine Recherches en Management, Paris, França

${ }^{2}$ Institut Mines-Télécom Business School, Paris, França

3HEC-Montréal, Département de Management, Montréal, Canadá

Texto submetido em ocasião do sexagésimo aniversário da RAE-Revista de Administração de Empresas, FGV EAESP; dedicado a todos os colegas brasileiros e de língua francesa que contribuíram ao longo deste intercâmbio nas últimas décadas.

\section{RESUMO}

O objetivo deste artigo é dar uma olhada na influência que as obras de língua francesa têm exercido sobre a comunidade acadêmica brasileira nas últimas décadas, a partir do conhecimento do autor e sua longa associação do campo das ciências administrativas brasileiras. Para isso, o artigo está dividido em três partes. A primeira lembra a relação que o autor estabeleceu com a comunidade brasileira para localizar quem está falando e onde ele está falando. A segunda discute brevemente o vínculo histórico que o Brasil mantém, de um modo geral, com o pensamento francês. A terceira apresentará as principais correntes intelectuais que parecem, segundo o autor, ter chamado a atenção dos pesquisadores brasileiros em ciências administrativas. Esta reflexão se conclui com algumas considerações sobre o futuro da área e alguns desejos sobre as futuras relações entre pesquisadores brasileiros e pesquisadores francófonos.

PALAVRAS-CHAVE | Ciências administrativas, Brasil, língua francesa, França, Québec.

\section{RESUME}

L'objet de cet article est de jeter un regard sur l'influence que les travaux de langue française ont exercé sur la communauté académique brésilienne au cours des dernières décennies à partir de la connaissance que l'auteur en a, suite à une longue fréquentation du champ des sciences administratives brésilien. Pour ce faire, l'article se divise en trois parties. La première procède à un rappel de la relation que l'auteur a établie avec la communauté brésilienne pour situer qui parle et d'où il parle. La deuxième aborde brièvement le lien historique que le Brésil entretient avec la pensée française en général. Et la troisième présente les principaux courants qui semblent, selon l'auteur, avoir retenu l'attention des chercheurs brésiliens en sciences administratives. Il se conclut cette réflexion par quelques considérations sur l'avenir du champ et quelques souhaits sur la relation future entre chercheurs brésiliens et chercheurs de langue française.

MOTS CLÉS / Sciences administratives, Brésil, langue française, France, Québec.

\section{ABSTRACT}

The object of this article is to take a look at the influence that French-language works have had on the Brazilian academic community over the past decades, based on the author's knowledge of it, and a long attendance of the field of Brazilian administrative sciences. To do this, the article is divided into three parts. The first recalls the relationship that the author has established with the Brazilian community to locate who is speaking and from where he is speaking. The second briefly discusses the historical link that Brazil maintains with French thought in general. And the third presents the French main intellectual currents, which, according to the author, seem to have caught the attention of Brazilian researchers in administrative sciences. This reflection ends with some considerations on the future of the field and some wishes on the future relationship between Brazilian researchers and French-speaking researchers.

KEYWORDS I Administrative science, Brazil, French language, France, Quebec. 
Esta edição especial celebra o sexagésimo aniversário da $R A E$, para a qual fui cordialmente convidado a contribuir por meio de sua editora-chefe, Maria José Tonelli, algo que para mim não é somente uma honra e um testemunho da longa relação que mantenho há mais de 30 anos com a comunidade brasileira de Ciências Administrativas, mas antes o reconhecimento dos vínculos intelectuais e amistosos que se consolidaram ao longo destes últimos anos com a comunidade de pesquisadores francófonos a que pertenço. Portanto, é em nome desse pertencimento intelectual e linguístico que tecerei, a pedido dos organizadores desta edição, um olhar acerca da influência que os trabalhos de língua francesa exerceram sobre a comunidade acadêmica brasileira ao longo destes últimos anos. Faço isso em um contexto histórico muito particular: a pandemia global que desafia nossas formas de desenvolvimento e se revela como uma verdadeira crise antropológica (Chanlat, 2020).

Este artigo divide-se em três partes. A primeira procederá ao retrospecto de minha relação com a comunidade brasileira a fim de lembrar quem vos fala e de onde fala. A segunda abordará brevemente o vínculo histórico que o Brasil mantém, de um modo geral, com o pensamento francês. Ao passo que a terceira apresentará as principais correntes intelectuais que parecem, a meu ver, ter despertado o interesse de pesquisadores brasileiros nas Ciências Administrativas. Concluiremos esta reflexão fazendo algumas considerações sobre as perspectivas de nossa área e alguns desejos sobre as futuras relações entre pesquisadores brasileiros e francófonos.

\section{MINHA DESCOBERTA DO BRASIL: UMA BREVE RECORDAÇÃO BIOGRÁFICA}

Antes de conhecer o País em sua realidade sensível, alimentei, como muitas outras pessoas no mundo todo, uma visão do Brasil parcialmente motivada por aquela imagem amiúde recorrente e estereotipada que se tem do País: a Amazônia, o Carnaval do Rio, a praia de Copacabana, o samba, o futebol etc. Quando criança, eu, de fato, assistira à retransmissão televisiva da Copa do Mundo de 1958 - uma primeira na época -, entre Brasil e França, e o surgimento de Pelé como um dos grandes jogadores da história desse esporte, e, claro, vi, ainda em 1964, o célebre filme francês $O$ homem do Rio, com Jean-Paul Belmondo no elenco. Contudo, eu também tinha adquirido uma outra imagem, proveniente de alguns conhecimentos de sua história e de suas peculiaridades sociológicas, durante os anos que vivi na HEC-Montréal, junto a um amigo e colega, Allain Joly (2004), que à época fazia seu doutorado na Fundação Getulio Vargas, Escola de Administração de Empresas de Sâo Paulo (FGV EAESP), no início dos anos 1980, e que desempenharia um papel determinante na minha relação com o Brasil.

A primeira vez que travei contato com um professor brasileiro na área das Ciências Administrativas foi em Montreal, durante o ano letivo de 1984-1985. Naquela época, ainda um jovem docente da HEC-Montréal, conheci Roberto Fachin, professor na Faculdade de Administração da Universidade Federal do Rio Grande do Sul (UFRGS). Roberto, uma autoridade da área no âmbito brasileiro, viera passar um ano sabático ali. Durante todo aquele ano letivo, discutimos longamente, por um lado, sobre a situação brasileira de um modo geral e, por outro, sobre o ensino em gestão, sobretudo à ocasião de um colóquio internacional importante sobre o tema, realizado na primavera de 1985 por meu irmão Alain e Maurice Dufour.

Em setembro de 1990, encontrei novamente, em Montreal, graças à mediação de Allain Joly, dois importantes professores da FGV EAESP, Ofélia Torres e Fernando Prestes Motta, os quais vieram participar do grande colóquio internacional que organizei sobre o trabalho que acabara de coordenar (Chanlat, 1990), após um ano sabático na França, e que rapidamente se tornaria uma obra de referência nos países de língua francesa (Nugent, 1993; Padioleau, 1992; Sciences Humaines, 1998). 
Após sua participação no congresso e o interesse manifestado pelos professores Torres e Motta na perspectiva desenvolvida nessa obra, hoje considerada pioneira (Bouville \& Yousfi, 2021), e o apoio financeiro fornecido pelo Centre d'étude en Administration Internationale (CETAI) da HEC-Montreal para a tradução, uma edição em português, dividida em três volumes, seria rapidamente organizada no Brasil por Ofélia Torres, com seus capítulos traduzidos por uma série de professores brasileiros, sobretudo da FGV EAESP (Chanlat, 1992, 1994, 1996). Em 1992, fui convidado, por iniciativa de Ofélia Torres, Roberto Fachin e Tânia Fischer, com o apoio do Conselho Nacional de Desenvolvimento Científico e Tecnológico (CNPq), a participar do lançamento do primeiro volume e a realizar, naquele mesmo ano, uma série de palestras no Brasil.

Essa primeira estadia de três semanas no Brasil levou-me sucessivamente à FGV EAESP, às Faculdades de Administração das Universidades Federais de Minas Gerais, do Rio Grande do Sul e da Bahia, bem como à Pontifícia Universidade Católica do Rio de Janeiro (PUC-Rio), e permitiu-me conhecer o Brasil - este país continental - em toda a sua diversidade humana e geográfica e suas divisões sociais. Tais viagens multiplicaram-se, e, por ocasião delas, reencontrei diversos colegas: Valmiria Carolina Piccinini, Ana Maria Kirschner, Maria Elisabeth Antunes Lima, Suzana Braga, Liliana Segnini, Marlene Catarina de Oliveira Lopes Melo, Alfredo Alves de Oliveira Melo, Juvêncio Braga de Lima, Tânia Fischer, José Antônio Gomes de Pinho, Silvia Vergara, Patricia Tomei, Clovis Machado †, Maria José Tonelli, Fernando Prestes Motta †, Sigmar Malvezzi, Maria Irene Betiol, Thomaz Wood Jr., Miguel Caldas, Bianor Cavalcanti, Eduardo Marques, Yann Duzert, Maria Ester de Freitas, Maria Teresa Fleury, Roberto Lima Ruas, Luiz Bignetti †, Fábio Bittencourt Meira, Isabella de Vasconcelos, Flávio de Vasconcelos, Angelo Soares, Guilherme Azevedo, Marlei Pozzebon, Eduardo Diniz, Rafael Alcadipani, Sidinei Rocha-de-Oliveira, que, em seguida se tornariam amigos; alguns deles viriam a ser meus alunos: Eduardo Davel, Gelson Junquilho, Jair Nascimento Santos, Carolina Andion, o saudoso José Roberto Gomes da Silva †, Maria Elisa Brandao, Marina Nakayama, Marcelo Dantas, Mauricio Serva, com os quais mantive, desde então, uma relação intelectual e amistosa.

Ao longo de todos esses anos passados em Montreal, Estrasburgo, depois Paris, e desde minha instalação final a universidade Paris-Dauphine, em setembro de 2001, eu retornarei regularmente o Brasil como palestrante convidado dos congressos da Associação Nacional de Pós-graduação e Pesquisa em Administração (ANPAD), de Estudos Organizacionais da ANPAD (EnEO), da Iberoamerican Academy of Management, dos colóquios internacionais da Universidade Federal da Bahia (UFBA) sobre Poder Local, organizados em Salvador pela professora Tânia Fischer e pelo Núcleo de Estudos sobre Poder e Organizações Locais (NEPOL) atualmente Centro Interdisciplinar de Desenvolvimento e Gestão Social (CIAGS), de um colóquio da Pontifícia Universidade Católica do Rio Grande do Sul (PUC-RS) de Porto Alegre, além de seminários e conferências em diversas instituições públicas e privadas de São Paulo, Belo Horizonte, Campinas, Brasília, São Leopoldo, Florianópolis, Porto Alegre, Salvador, Rio de Janeiro, Vitória etc. Nessas ocasiões, amiúde aproveitava para participar de diversas bancas de doutorado, ou mesmo co-orientar algumas teses, inclusive aquela do saudoso José Roberto Gomes da Silva † (2010), cuja desaparição trágica esteve associada, como todos sabem, a esta relação franco-brasileira (Chanlat, 2010b). A atividade desempenhada como orientador de pesquisadores brasileiros continuaria em Paris, onde tive o prazer de orientar uma pesquisa de mestrado, a dissertação de Simone Cota, orientei a tese de Virginia Drummond, e supervisionei, durante sua estada de pós-doutorado, Rodrigo Bandeira de Mello, que depois se juntaria todo ano a nossa unidade de ensino e pesquisa. Ainda em Paris, pude participar das bancas de doutorado de Teresa Bicalho de Menezes, outra brasileira doutoranda pela Dauphine, orientada pelo meu colega, professor Jacques Richard, das de Bibiana Volker Martins e de Laura Scherer, doutorandas pela UFRGS de Porto Alegre, as quais eu havia previamente recepcionado no âmbito de uma bolsa-sanduíche. 
Durante todos estes anos, várias outras obras de minha autoria seriam traduzidas (Chanlat, 2000, 2010a), bem como alguns artigos publicados nas revistas: RAE, Organização e Sociedade, Gestão e Planejamento, Cadernos EBAPE.BR, GV executivo; alguns capítulos apareceram em diversas outras obras (Bendassolli \& Soboll, 2010/2021; Davel \& Melo, 2005; Davel \& Vergara, 2001). Por fim, pude codirigir, junto a meus colegas e amigos Roberto Fachin e Tânia Fischer, dois importantes trabalhos: Análise das organizações: Perspectivas latinas, Vols. 1 e 2, que retomaram uma série de comunicações feitas sobre o tema durante um colóquio memorável, realizado em julho de 2000 em Zacatecas, no México, organizado por nossos colegas e amigos mexicanos dos estudos organizacionais da UAM-Iztapalapa (Ramirez Martinez \& Gonzáles-Miranda, 2018; Gonzáles-Miranda e Ramirez Martinez, 2018, 2020) e eu, e que naquela ocasião havia reunido colegas reconhecidos de diversos países francófonos (França, Bélgica, Canadá), hispano-falantes (México, Colômbia, Argentina) e brasileiros (Chanlat, Fachin, \& Fischer, 2006, 2007; Fachin, 2014).

Como se pode perceber, foram essas inúmeras estadas em terras brasileiras que me permitiram paulatinamente me familiarizar com o País e adquirir uma muita bom visão do campo das Ciências Administrativas, um olhar franco-quebequense, em virtude de minha própria trajetória intelectual e profissional. A cada nova estada, constatei o quanto o pensamento francês era então levado a sério, e o quanto os trabalhos em língua francesa sobre organizações, trabalho e economia despertavam interesse no País.

\section{A ABERTURA BRASILEIRA AO PENSAMENTO FRANCÊS: UMA HISTÓRIA ANTIGA}

Quando estive pela primeira vez no Brasil, constatei de imediato a influência que o pensamento francês historicamente havia exercido e, de fato, ainda exerce na sociedade brasileira. Fiquei particularmente impressionado com a quantidade de colegas das Ciências Administrativas que dominavam a língua francesa ou compreendiam o idioma sem, no entanto, falarem.

De acordo com alguns pesquisadores brasileiros e estrangeiros, essa influência francesa remonta ao século XVIII, devido ao pensamento dos filósofos iluministas franceses, e atravessa o século XIX com a difusão das ideias de Auguste Comte sob a iniciativa de Miguel de Lemos, Benjamin Constant Botelho de Magalhães e de Raimundo Teixeira Mendes (Grange, 2000; Lins, 1967), escola de pensamento da qual pude ver alguns vestígios arquitetônicos em sua primeira igreja positivista do Rio, erigida em 1881, alguns anos antes da proclamação da República. Ainda, podemos encontrar um traço eloquente de Comte no próprio lema do Brasil, "Ordem e Progresso", que, por sua vez, nos remete a uma máxima comtiana (Tyr, 2007). A filosofia de Comte era, então, vista como uma fonte de inspiração para as elites modernistas que aspiravam a fundar uma República e pôr fim à escravidão, tal como sublinhado por Lorelai Kury a esse respeito:

O projeto político positivista, republicano e autoritário, foi muito influente no Brasil, particularmente poderoso na virada do século XIX para o século XX. Os discípulos de Auguste Comte de fato venceram, em 1889, a batalha simbólica em torno da bandeira nacional republicana: o modelo, proposto por Raimundo Teixeira Mendes, adicionava à antiga bandeira Imperial a divisa "Ordem e Progresso", destinada a estabelecer uma conexão entre o passado e o futuro, graças àqueles que seguiam de perto as ideias do filósofo francês. Muito embora o posi- 
tivismo tenha perdido, ao longo do século vinte, a influência de que gozava outrora, todavia essa corrente de pensamento legou profundas marcas ideológicas às classes médias urbanas do país. (Kury, 2003, p. 126)

Em pleno século XX, essa influência francesa ainda persistiria. Ela esteve relacionada à criação de Universidade de São Paulo (USP), nos anos 1930, à qual se associarão marcantes personalidades francesas, tais como os geógrafos Pierre Monbeig e Pierre Deffontaines, o historiador Fernand Braudel, o etnólogo Claude Lévi-Strauss, o sociólogo e antropólogo Roger Bastide, o filósofo François Châtelet, os historiadores Gérard Lebrun e Jean-Pierre Vernant, o epistemólogo Gilles-Gaston Granger e, de um modo geral, a forte influência que a filosofia francesa exerceria numa disciplina de destaque no País ao longo daquele século.

Como recordou Sérgio Paulo Rouanet (2010), à ocasião do ano do Brasil organizado na França em 2010:

A influência francesa foi de tal modo predominante que uma história da recepção das ideias filosóficas francesas se confunde, em larga medida, com a própria história da filosofia no Brasil. Para demonstrar essa hegemonia, basta citar um livro recente sobre o ensino de filosofia na Universidade de São Paulo (USP), uma das instituições mais respeitadas no Brasil e fundada sob os auspícios de professores franceses. Seu autor menciona o Departamento de Filosofia da Universidade como “Departamento francês do ultramar”: isso já diz tudo. (p. 41)

É assim que o pensamento de Bergson, o humanismo integral de Maritain, o personalismo de Mounier, o estruturalismo de Lévi-Strauss, o existencialismo de Sartre e, mais tarde, os trabalhos de Castoriadis, de Foucault, de Derrida e de Deleuze se sucederão, de acordo com as tendências específicas de cada um dos períodos em questão,, e gozarão de grande prestígio no seio das elites intelectuais brasileiras. A partir dos anos 1970, eles se conjugarão ao entusiasmo com que a comunidade brasileira olhará para as Ciências Sociais francesas, que tiveram grande reconhecimento internacional, e às relações que grandes intelectuais brasileiros - como Fernando Henrique Cardoso - estabeleceram com importantes figuras francesas, sobretudo com Alain Touraine (Kirschner \& Gomes, 2014b). Portanto, o pano de fundo da intelectualidade brasileira foi nitidamente marcado pelos sucessivos traços históricos deixados pelo pensamento francês, a despeito de outras correntes de pensamento - sobretudo aquelas de línguas inglesa e alemã - que, posteriormente, adquiriram um maior protagonismo, notadamente nas últimas décadas (Rouanet, 2010).

Devido a essa atração histórica que a cultura francesa imprimira no seio das elites (Fachin \& Cavedon, 2003), um fenômeno que se pôde, via de regra, observar em outros países da América Latina (Bonnafous, 1953), esse substrato histórico se revelará de maneira favorável a partir do fim do século XX, com uma abertura maior a produções em língua francesa de obras que versavam sobre trabalho, organizações e economia. Tal fenômeno será favorecido pelo fato de que muitos professores brasileiros viriam a fazer seus estudos de doutorado na França e, mais tarde, também na província de Quebec, num momento em que a comunidade brasileira das Ciências Administrativas buscava, entre outras coisas, algumas alternativas ao pensamento anglo-saxão dominante nessa área do conhecimento (Bertero, Caldas, \& Wood, 1999; Cassundé, Barbosa \& Mendonça, 2016; Fachin, 2014; Fachin \& Cavedon, 2003; Fischer, 1985; Motta, 1990; Paula, Maranhão, Barreto, \& Klechen, 2010; Torres \& Gonçalves, 1991; Vergara, 2006; Waiandt, 2018). 


\section{PESQUISADORES BRASILEIROS DAS CIÊNCIAS ADMINISTRATIVAS EM BUSCA DE UMA ALTERNATIVA À HEGEMONIA ANGLO-SAXÃ}

Quando consultamos trabalhos brasileiros, sobretudo aqueles que buscam fazer uma síntese de sua disciplina no âmbito das Ciências Sociais (Bendassolli \& Soboll, 2010/2021; Kirschner \& Gomes, 2014a, 2014b;) e das Ciências Administrativas (Bertero, 2006; Bertero, Alcadipani, Cabral, Faria, \& Rossoni, 2013; Bertero, Caldas, \& Wood, 2005), observamos que as publicações em língua francesa são, a despeito da prevalência de trabalhos anglo-saxões, muito presentes em suas reflexões, em especial dos pesquisadores brasileiros que buscam uma alternativa à predominância de referências anglo-estadunidenses (Fachin, 2014; Vergara, 2006; Vergara \& Pinto, 2001; Waiandt, 2018).

No campo das Ciências Administrativas, essa hegemonia remonta aos anos 1950, ocasião em que os governos estadunidense e brasileiro firmaram acordos a fim de estabelecer os primeiros programas de ensino e de criar as primeiras instituições de ensino superior em gestão, imersos no contexto da Guerra Fria e com ajuda da Fundação Ford, profundamente inspiradas pelo modelo estadunidense de formação acadêmica (Alcadipani \& Bertero, 2012, 2014; Alcadipani \& Caldas, 2012; Alcadipani \& Cooke, 2013; Barros, Alcadipani \& Bertero, 2018; Serva \& Andion, 2021).

No Brasil, essa inflexão inscreve-se em um contexto muito mais amplo de uma sociedade historicamente aberta a ideias vindas de fora, conformando esse fenômeno que os brasileiros denominam: "O Estrangeirismo" (Buarque de Holanda, 1936; 1998; Caldas \& Wood, 1997; Freyre, 1963; Motta, Alcadipani, \& Bresler, 2001; Bartel-Radic, 2013), muitas vezes caracterizado pragmaticamente por uma espécie de antropofagia das práticas estrangeiras (Davel, Dantas, \& Vergara, 2008; Bartel-Radic, 2013).

Em nossos dias, tal situação afigura-se, de acordo com alguns colegas (Bertero et al., 2013), da seguinte maneira:

... A imensa maioria dos estudos em Administração no Brasil, principalmente em áreas como estudos organizacionais e ensino e pesquisa, é constituída por ensaios teóricos focados em autores Europeus.... Parece que uma grande parcela dos estudiosos do campo tem horror a ir a campo e, quando o fazem, produzem textos com metodologia fraca e inconsistente. Ser atento ao nacional é ir à "realidade" brasileira, estudar a "realidade" brasileira, conhecer a "realidade" brasileira, com referências que possibilitem à realidade se expressar em sua complexidade e não ser tolhida e escondida atrás de teorias e modelos. Estudamos muito pouco a Administração no Brasil. Um dos motivos de nossa falta de originalidade deve-se ao fato de olharmos muito pouco para a nossa realidade, para o que acontece no Brasil. Porém, o paroquialismo de alguns setores é compensado pelo estrangeirismo de outros .... Temos uma tendência de supervalorizar o estrangeiro .... Valorizar o ensino e a pesquisa do Norte como de "primeira linha" é fundamental para a construção de nossa inferioridade como pesquisadores, implica deixar para eles o papel de criar modelos e refletir e posicioná-nos como meros reprodutores (p. 186).

A partir dessa dura constatação, eles ressaltam de passagem o papel desempenhado pelo mercado de publicações: 
Mais importante do que isso, é preciso ter em mente que muito do mercado de publicações acadêmicas, tido como "internacional", é controlado por editoras anglo-saxãs e por acadêmicos anglo-saxões. Se pegarmos aqueles que são tidos como os principais periódicos da área, quase que apenas são publicados artigos de temáticas específicas produzidos em universidades específicas. Publicar em um periódico internacional envolve trabalho acadêmico sério, mas também envolve questões de poder. Vejo, hoje, muitos acadêmicos de diferentes partes do mundo procurando um "broker" anglo-saxão para que seus artigos possam ser publicados nos tais periódicos de renome. Com isso, privilegia-se o gringo superior e permanece nossa condição de subalternos. Muitos dos gingos acreditam, de fato, que somos inferiores. (Bertero et al., 2013, p. 186)

Consequentemente, para esses mesmos autores:

Existe um pensamento hegemônico no campo, principalmente de origem norte-americana, que tende a desconsiderar perspectivas qualitativas e abordagens mais reflexivas. Ser norte-americano não significa seguir essa visão restrita e restritiva da pesquisa no campo. Há norte-americanos que defendem uma visão mais plural, assim como temos latinos que defendem uma visão mais restritiva de pesquisa no campo. 0 que percebo é um choque internacional entre as visões. (Bertero et al., 2013, p. 193)

É justamente nesse contexto histórico que alguns pesquisadores brasileiros empreenderão, a partir dos anos 1960, uma busca pelo desenvolvimento de pensamentos originais. Esse é o caso de Guerreiro Ramos (1981/1989, 1983; Azevedo \& Albernaz, 2006; de Paula, 2007; Serva, 1997a, 1997b; Serva \& Andion, 2021), de Mauricio Tragtenberg ou de Fernando Prestes Motta (Segnini \& Alcadipani, 2014), os quais encontrarão respaldo, no caso do primeiro, sobretudo no humanismo integral de Jacques Maritain e no personalismo de Emmanuel Mounier (Azevedo \& Albernaz, 2006), ao passo que, para os dois últimos, em outras tradições intelectuais francesas, notadamente anarquistas (Motta, 1981, 1984, 1990, 2003; Tragtenberg, 2005, 2010, 2012). Esses três autores brasileiros ostentam uma influência muito significativa no Brasil (Harzing, 2016). Outros autores, como Fachin e Cavedon (2003), ao final de seu artigo que versa justamente sobre a influência do pensamento francês nos Estudos Organizacionais brasileiros, não hesitam em sublinhar o interesse de tais leituras:

Em conseqüência, há que buscar, na francofonia, o influxo daquela produção acadêmica que, com embasamento em certas áreas seletivas do conhecimento, traduz o pensamento crítico francês tão caro aos intelectuais brasileiros de todos os setores. E, sem dúvida, a disponibilidade de tais obras em língua portuguesa representa substancial acréscimo às possibilidades de leitura dos acadêmicos brasileiros, que não tiveram formação pós-graduada na França ou no Quebec (p. 11).

Se o campo brasileiro da Ciências Administrativas recebeu a influência de inúmeros trabalhos de língua francesa, decidi, para fins deste artigo, considerar aqui, sem, no entanto, hierarquizar, as três disciplinas que foram, a meu ver, suas fontes inspiradoras, ou seja: as Ciências das Organizações, as Ciências do Trabalho e as Ciências Econômicas heterodoxas. Esse fenômeno foi encorajado pelo bilinguismo de inúmeros pesquisadores 
brasileiros, bem como pela tradução de diversas obras de referência nessas três disciplinas devido ao trabalho de editores brasileiros.

\section{As Ciências das Organizações}

A primeira fonte de inspiração vem das Ciências das Organizações, fruto do desenvolvimento de trabalhos associados ao surgimento das organizações como fato social no início dos anos 1960 (Caldas, Fachin, \& Fischer,1999; Clegg \& Bayley, 2007; Clegg, Hardy \& Nord, 1999; 2001, 2004; Chanlat \& Séguin, 1987; Etzioni, 1967; Perrow, 1976; Gonzáles-Miranda \& Ramirez Martinez, 2020; Séguin \& Chanlat, 1983; Saussois, 2016).

No contexto francófono, sobretudo francês, isso se traduzirá por um conjunto de pesquisas que se debruçariam sobre quatro grandes eixos temáticos: a Psicossociologia das organizações e a análise institucional, a Sociologia das organizações e de empresas, a Antropologia das organizações e a gestão das organizações.

Entre os inúmeros trabalhos publicados no âmbito francófono (Chanlat, 1992b, 1994, 2014; Stokes, Davoine \& Oiry, 2014; Entreprises et Histoire, 2016), os pesquisadores brasileiros vão ao cerne da corrente psicosociológica, aliás muito rica (Barus-Michel, Enriquez, \& Lévy, 2002), de modo a privilegiar os trabalhos de análise institucional (Lapassade, 1989; Lourau, 1975; Rossi \& Passos, 2014), de autores como Eugène Enriquez (1990, 1997, 2007, 2014), Max Pagès, Bonetti e de Gaulejac (1987), Nicole Aubert e Vincent de Gaulejac (1993; de Gaulejac, 2005) e Gilles Amado (2013), tal como corroboram Newton Garcia de Araújo e Andrade de Barros em sua recente revisão (2019). Esses últimos autores exercerão uma influência sobre a visão que os pesquisadores brasileiros construiriam a respeito da relação da vida psíquica e da organização, bem como inspirarão, tal como outros tantos pesquisadores de língua francesa (Didier Anzieu, Serge Moscovici, Jean-Claude Rouchy, Guy e Jacqueline Palmade, André Green, Laurent Lapierre etc.), o campo dos Estudos Organizacionais críticos brasileiros a partir dos anos 1990 (Bendassolli \& Soboll, 2011/2021; Freitas, 1999b; Freitas \& Motta, 2000).

Uma outra corrente de pesquisa em que os investigadores brasileiros concentrarão suas atenções remete justamente à Sociologia das organizações. Essa disciplina, fundada na França por Michel Crozier no início dos anos 1960, será objeto de um notável desenvolvimento nos países francófonos e latinos, impelido pelos trabalhos conduzidos pelo Centro de Sociologia das Organizações (CSO), criado e dirigido por Crozier (1963a e b; 2000; Crozier \& Friedberg, 1977; Entreprises et Histoire, 2016), se converterá na meca da maioria dos francófonos pioneiros nessa disciplina (Chanlat, 1992b, 1994; Saussois, 2016) e influenciará alguns trabalhos brasileiros, sobretudo no âmbito da Administração Pública (de Vasconcelos \& Pinochet, 2004). Ela igualmente beneficiará os estudos do Laboratório de Sociologia da Mudança das Instituições (LSCI), criado e dirigido por Renaud Sainsaulieu (1977/2014, 1990, 1997, 2002), um dos primeiros colaboradores de Crozier no CSO, e dos estudos do Grupo Lionês da Sociologia Industrial (GLYSI), criado e dirigido por Philippe Bernoux (1985; Amblard, Bernoux, Herreros, \& Livian, 1995). É do âmago da Sociologia das Organizações que emergirá, voltando novamente aos anos 1990, a Sociologia da empresa (Bélanger \& Lévesque, 1996; Dupuis \& Kuzminski, 1998; Sainsaulieu, 1990; Sainsaulieu \& Segrestin, 1987; Segrestin, 1992), disciplina responsável por desempenhar um papel muito importante no Brasil no início dos anos 2000 (Kirschner \& Gomes, 2014a; Sainsaulieu \& Kirschner, 2006).

A partir do início dos anos 1990, uma outra leva de trabalhos terá grande popularidade no âmbito das Ciências Administrativas brasileiras: as obras que serão associadas à minha própria perspectiva antropológica. Elas estão compiladas nos três volumes da edição brasileira Indivíduo na organização: Dimensões esquecidas que dirigi (em francês: L'individu dans l'organisation: les dimensions oubliées, dois outros livros traduzidos, um tra- 
ARTIGOS | INFLUÊNCIA DO PENSAMENTO DE LÍNGUA FRANCESA NA ACADEMIA BRASILEIRA DE ADMINISTRAÇÃO: UM OLHAR FRANCO-QUEBEQUENSE Jean-François Chanlat

duzido por Ofelia Torres (2000) e um outro publicado por Isabela de Vasconcelos em sua coleção "Debates em Administração" (2010) e em diversas outras publicações (Serva \& Andion, 2021). Tal como Ofélia Torres e Marilson Alves Gonçalves (1991) sublinharam na resenha que fizeram para a obra:

O livro L'individu dans l'organisation: Les dimensions oubliées transmite de forma magistral a mensagem de renovação dos conhecimentos e das práticas da ciência do comportamento no mundo dos negócios. A partir de uma reflexão geral sobre o desenvolvimento de uma antropologia da condição humana nas organizações, cada autor desenvolve sua contribuição em uma perspectiva particular. Da linguagem ao espaço, passando pelo universo simbólico, o tempo, a vida psíquica, a alteridade e a psicopatologia, a obra em questão atinge, assim, o objetivo a que se propôs, ou seja, o de estabelecer uma visão comum do ser humano, reconhecendo a importância do seu papel em cada dimensão sem, todavia, cercear o choque de ideias e de estilos e a liberdade de discordância quanto a métodos e abordagem em torno do tema comum... Tratando-se de uma publicação que abre novas perspectivas, ela interessa tanto aos professores e pesquisadores quanto a estudantes sobretudo mestrandos e doutorandos, numerosos hoje no Brasil, pois pode servir de referencial ao desenvolvimento de monografias e teses aplicadas a este novo campo de conhecimento. Pelo seu conteúdo reflexivo e prático sobre o ser humano nas organizações, enquanto sujeito, ator ou pessoa viva e concreta, não pode deixar de interessar também aos executivos e gestores de recursos humanos nas empresas. (pp. 107-108)

Em outras palavras, essa perspectiva levará os pesquisadores brasileiros a se interessarem pelas diferentes dimensões formuladas no trabalho de inúmeros colegas francófonos graças à sua edição brasileira (Fachin \& Cavedon, 2003; Torres \& Gonçalves 1992; Vergara, 2006), e a conferir um viés local a esses estudos (Chanlat, Fachin, \& Fischer, 2006). Tal perspectiva não ser etnocêntrico; nosso trabalho também inspirará uma miríade de reflexões no âmbito da epistemologia das Ciências Administrativas em pleno desenvolvimento (Serva \& Andion, 2021).

Por fim, alguns trabalhos em Ciências de Gestão também suscitarão um notável interesse em meio à comunidade brasileira. Podemos sublinhar, entre outros, a obra de síntese crítica de Omar Aktouf sobre gestão, na esteira dos estudos conduzidos à época pelo HEC-Montréal (Chanlat, 1990; Chanlat \& Dufour, 1985), cuja tradução em português terá grande difusão no Brasil (1996); alguns trabalhos do CRG da Escola Politécnica de Paris (Berry, 1983, 2011), sobretudo aquele de Jacques Girin (2016) sobre a linguagem e as situações de gestão (Bayard, Borzeix, \& Dumez, 2010), e de Hervé Dumez (2016) sobre as metodologias qualitativas; os trabalhos de Audet e Malouin (1986), de Audet e Déry (1996) em Quebec, e de Martinet (1990) e de Pesqueux na França sobre a epistemologia das Ciências de Gestão (Martinet \& Pesqueux, 2013; Serva, 2013, 2017 a et b) e Pesqueux sobre filosofia e organizaçoes (2008); aqueles de Thévenet (1992) sobre a cultura empresarial; e as obras pioneiras de Philippe d'Iribarne e sua equipe, "Gestão e Sociedade" (“Gestion et Société"), sobre a cultura nacional (d'Iribarne, Chevrier, Henry, Segal, \& Tréguer-Felten, 2020; d'Iribarne, Henry, Segal, Chevrier, \& Globokar, 1998); aquelas de Jean-Pierre Dupuis, Serge Bouchard e Omar Aktouf sobre a cultura e a simbolismo organizacional (Freitas, 1991; 1999a), bem como os trabalhos de Laurent Lapierre sobre liderança (1989, 2005), estes últimos notavelmente apresentados em Chanlat (1992, 1994, 1996); ou, ainda, aqueles de Romain Laufer (1977) sobre a crise da legitimidade das organizações (Laufer \& Paradeise, 1982; Motta, 1988). 
Mais recentemente, podemos citar as obras da École des Mines, sobretudo de Segrestin e Hatchuel (2012) acerca da redefinição da empresa, responsáveis por despertar um certo entusiasmo entre vários pesquisadores interessados na gestão de organizações solidárias (Eynaud \& França, 2019, 2020) e por contribuir com a redefinição jurídica das empresas na França (Hatchuel, 2021), um tópico que também é visto como fundamental por muitos pesquisadores da linguagem inglês (Clarke, O'Brien \& O'Kelley, 2019); aquelas da "Chaire Management, diversité et cohésion sociale", da Universidade Paris-Dauphine, conduzidas por Stéphanie Dameron, Mustafa Özbilgin e 0 autor deste artigo ao longo de 10 anos (2008-2018) (Chanlat et al., 2013; Chanlat \& Özbilgin, 2018, 2019), cujos trabalhos e os dois Simpósios Internacionais, organizados em Paris em 2011 e 2015, terão grande repercussão no Brasil, com a participação de Maria Ester de Freitas e de Marcelo Dantas, graças aos contatos estabelecidos naquela ocasião com alguns outros pesquisadores. Desde então, no âmbito das Ciências Administrativas, uma nova esfera de pesquisa emergirá do campo da interculturalidade (Davel, Dupuis, \& Chanlat, 2008) e da diversidade, e que buscará uma melhor compreensão, em particular, das experiências de expatriação e redução das desigualdades e discriminações vividas no mundo das organizações brasileiras (Bueno \& Freitas, 2016; Freitas, 2018; Freitas \& Dantas, 2011; Freitas \& Dantas, 2014).

Podemos citar, ainda, os trabalhos fundamentais, embora recentes, sobre Contabilidade, conduzidos por Alexandre Rambaud e Jacques Richard, que questionam os próprios fundamentos da disciplina com vistas a reformular nosso sistema econômico, e deverão angariar o interesse dos pesquisadores brasileiros na busca de um modelo de gestão ecológico em virtude das relações que Jacques Richard estabeleceu com alguns pesquisadores brasileiros (Rambaud \& Richard, 2021) o os de David, Hatchuel \& Laufer trabalhando para lançar novas bases para as ciências da gestão (2012) e, não menos importante, os inúmeros trabalhos das redes científicas francófonas, tais como a RIODD, sobre a responsabilidade das empresas e desenvolvimento sustentável, a AGRH (Gestão de Recursos Humanos), a AIMS (Gestão Estratégica e Organização), a RHIME (Ética e Interdisciplinaridade) e a Atlas-AFMI (Gestão Internacional), as quais os pesquisadores brasileiros e francófonos podem acessar via internet e participar livremente, como alguns, de fato, fizeram nas últimas décadas. Enfim, os pesquisadores podem consultar diversas revistas que lhes darão acesso a trabalhos amiúde originais, tais como a Revue Française de Gestion, Gérer et Comprendre, Gestion, Management International, Management et Avenir, Finance, Contrôle, Stratégie, M@n@gement, Rhime, le Libellio d'Aegis, Entreprise et Société, Revue internationale PME, Gestion 2000, La Revue des Sciences de Gestion, Management et Sciences Sociales, Revue de l'organisation responsable, Question(s) de management, Entreprises et histoire, e consultar o site da Société Française de Management para ler suas resenhas, seus pareceres e publicações sobre questões da atualidade referentes à nossa área de atuação.

\section{As Ciências do Trabalho}

As Ciências do Trabalho constituem a segunda fonte de inspiração. A obra de Christophe Dejours (2007, 2011, 2015, 2017) ocupa, no Brasil, um lugar histórico central (Dejours, Abdoucheli, \& Jayet, 1994). Sua perspectiva da Psicodinâmica do Trabalho, de fato, dará grande fôlego às pesquisas brasileiras sobre Psicologia do Trabalho a partir dos anos 1990 (Aerosa, 2019; Bendassolli \& Borges-Andrade, 2015; Bendassolli e Soboll, 2010/2021; Betiol \& Tonelli, 2002; Cicero, Cardoso, \& Klipan, 2019; Lima, 1998; Sznelwar, Uchida, \& Lancman, 2011). Tal como sublinhado em 2009 por Álvaro Roberto Crespo Merlo e Ana Magnólia Bezerra Mendes (2009) em um inventário da Psicodinâmica do Trabalho no Brasil: 
O lançamento no Brasil do livro A loucura do trabalho, de Christophe Dejours, em 1987, com o novo aporte teórico trazido pela obra, tornou-se referência para quase todos os pesquisadores que atuam na área. A discussão e a abordagem apresetadas nesse livro eram novas, trouxeram muitas respostas e abriram caminhos para que se pudesse pensar as consequências do trabalho - em especial pela forma como ele trabalho está organizado - sobre a saúde psíquica dos trabalhadores. (p. 142)

Em outra passagem, os autores complementam:

A abordagem adotada por essa disciplina permitiu ultrapassar uma visão reducionista que responsabilizava apenas o indivíduo pelas consequências do trabalho sobre sua saúde e buscar vivências operárias específicas, que se inscrevem em realidades concretas de trabaIho, como, por exemplo, o papel da inteligência operária e sua função como mecanismo de defesa e na construção de identidade no trabalho. (Merlo \& Mendes, 2009, p. 143)

Em virtude de seu lastro ancorado na prática, essa abordagem exercerá, igualmente, uma notável influência sobre as Ciências Administrativas por parte de pesquisadores e pesquisadoras interessados na relação entre Psicologia e organização (Fachin \& Cavedon, 2003; Freitas, 2008a; Freitas \& Motta, 2000; Vergara, 2006), também por meio do capítulo que o referido autor redigira em minha principal obra (Dejours, 1996).

Outras publicações no campo das Ciências do Trabalho também despertarão o interesse, e aqui podemos evocar aquelas de Pascale Molinier (2013) sobre o emprego na área de serviços e de assistência (Gaviria \& Molinier, 2011), por muito tempo próximo de Dejours, as produções de Yves Clot (2010) e de Dominique Lhuillier, responsáveis por desenvolver uma clínica da atividade laboral inspirada em Vitgovsky e Bakthin (Bendassolli \& Soboll, 2011/2021; Clot \& Lhuillier, 2006, 2010; Lima, 2013), e os trabalhos pioneiros em Ergonomia conduzidos por Alain Wisner, fundador da Escola Francesa de Ergonomia (Sznelwar, 2006). Por fim, algumas produções de Sociologia do Trabalho, em certa medida, também tiveram repercussão. Podemos citar, particularmente, a teoria da regulação social de Jean-Daniel Reynaud (1989), uma referência central no âmbito francófono (Terssac, 2003) e que gozará de reconhecimento por parte dos colegas que se dedicam às Ciências Administrativas no Brasil, sobretudo por Marlene Catarina Oliveira Lopes Melo (1984), que, tendo feito sua tese sob a orientação de Reynaud, o utilizará para compreender o papel desempenhado pela participação na gestão de conflitos no trabalho, observação que também pode ser feita aos colegas francófonos (Richebé et al., 2020). Finalmente, podemos mencionar os trabalhos de Norbert Alter sobre inovação (2002) e cooperação (2010), que também não passaram despercebidos pela comunidade brasileira (Salvador, 2011).

\section{As Ciências Econômicas heterodoxas}

A terceira fonte de inspiração para os pesquisadores brasileiros nas Ciências Administrativas são as Ciências Econômicas heterodoxas (Lévesque, Bourque, \& Forgues, 1997). De fato, todos aqueles e todas aquelas que se interessam pelo equilíbrio socioeconômico, desenvolvimento social e organizações de economia social em um país onde existem profundas desigualdades sociais (Ferreira de Souza, 2018), encontraram, no pensamento econômico heterodoxo francês, os elementos capazes de suscitar o enriquecimento de suas próprias reflexões sobre as realidades brasileiras. 
Entre essas correntes, podemos citar aquelas que orbitam em torno da Teoria da Regulação: Boyer, Freyssenet, Aglietta, Coriat, Lipietz, Orléan... (Aglietta, 1997; Boyer \& Cohen, 2010; Coriat, 1994; Mello, 2019), bem conhecida na América Latina (Castaingts-Teillery, 2014; de Mello Filho, 2019), e da Economia das Convenções (Boltanski \& Chiapello, 1999; Boltanski \& Thévenot, 1991; Eymard-Duvernay, 2004; Favereau, 1989; Salais \& Thévenot, 1986; Orléan, 2004), a análise das convenções constituída como uma teoria da ação coletiva que busca superar as contradições da teoria da escolha racional (Bessy \& Favereau, 2003).

Os trabalhos dessa última corrente, sobretudo aqueles de Boltanski e Thévenot (1991) sobre a Economia das Grandezas, conferem uma atenção central referente à situação na qual a ação coletiva se inscreve, sendo ela constituída, segundo os autores, pelos processos de justificações e testes; desse processo surge uma pluralidade de sentidos sobre o que é justo por meio de diversos modelos de “mundos” (mercado, doméstico, industrial, cívico, de opinião e de inspiração), sem que haja uma hierarquia externa ou determinada entre eles; portanto, a existência dessa pluralidade de convenções permite uma crítica à visão meramente mercadológica. Esses trabalhos, ao se juntarem às reflexões de certo número de pesquisadores brasileiros em torno da racionalidade substantiva, na esteira do trabalho pioneiro realizado no Brasil por Guerreiro Ramos, terão alguma repercussão junto a esses últimos (Serva, Caitano, Santos, \& Siqueira, 2015).

Uma vez que a Economia Social constitui uma área importante no Brasil, os trabalhos conduzidos no âmbito francófono nessa disciplina também despertarão grande interesse na comunidade de pesquisadores brasileiros, assim como os trabalhos brasileiros suscitarão um grande interesse na França e no Quebec (Laville, 2011). A Teoria das Organizações, até agora, não tem se mostrado deveras interessada nas organizações da economia solidária (Serva, 2002; Serva \& Andion, 2006), todavia não surpreende, portanto, que alguns pesquisadores brasileiros se inspirem nessa corrente de Sociologia Econômica aportando-lhe suas originais contribuições (Andion, 2002, 2005; França, Laville, Medeiros \& Magnen, 2005; Martes, Loureiro, Abramovay \& Serafim, 2007; Sperb \& Serva, 2018). Os colóquios internacionais sobre Poder Local, realizados na Bahia pela NEPOL, atual CIAGS, e coordenados por Tânia Fischer, favorecem em muito sua difusão. $O$ recente trabalho de Philippe Eynaud e de Genauto Carvalho de França Filho, membro do CIAGS, Solidariedade e organizações: pensar uma outra organização, publicado na França (2019) e no Brasil (2020) (edição francesa original: Solidarité et organisation: penser une autre gestion) à sua maneira, é um testemunho exemplar da cooperação franco-brasileira sobre essa temática fundamental tanto para a gestão quanto para o futuro socioeconômico e ambiental. Eles sublinham os potenciais e, ao mesmo tempo, os paradoxos da seguinte maneira:

... Ante esses perigos ameaçadores, tão somente uma única solução . . . pode ser invocada: a solidariedade. A defesa de uma solidariedade entre os homens e a natureza (entendida como a totalidade dos seres vivos: animais e vegetais) é, com efeito, o meio mais direto de fazer frente aos desafios, tais como aqueles das mudanças climáticas e da perda da biodiversidade. 0 desenvolvimento de uma solidariedade entre os próprios homens é também uma resposta perene às desigualdades que os dividem. Contudo, se o enunciado da resposta é fácil, sua execução é particularmente difícil. Ela é confrontada por inúmeros obstáculos, entre eles - e não menos importante - a carência de reflexão sobre os conceitos mobilizáveis para organizar esta solidariedade o mais próximo possível dos atores e de suas atividades econômicas. Há, portanto, um paradoxo que deve ser desde já destacado: nunca a solidariedade careceu tanto de execução nos âmbitos nacional e internacional, e a reflexão sobre ela nunca foi tão eludida, desconhecida, quando não desacreditada. (p. 5) 


\section{ENTRE O LOCALISMO E A ABERTURA: O ÂMBITO BRASILEIRO EM BUSCA DE SUA SINGULARIDADE NO ÂMBITO INTERNACIONAL?}

As Ciências Administrativas brasileiras desde sempre conheceram, como acabamos de ver, as influências estrangeiras, o que não é nada surpreendente neste mundo científico tradicionalmente marcado pela circulação de ideias. Embora esse intercâmbio se mostre muito fecundo, persiste o fato de que algumas situações podem ser problemáticas quando uma forte dominação se exerce em determinado campo, impedindo-o de se desenvolver de acordo com seu ritmo e segundo seus próprios questionamentos. Esse atualmente é o caso de diversas áreas nacionais, que são cada vez mais, sob pressão das regras e lógicas ditas "internacionais", implantadas na esteira do universo norte-americano, que a ele se conformam. Contudo, tal fenômeno não é somente vivido nos países do Sul, ele afeta igualmente diversos outros países no mundo, inclusive os anglófonos (Clegg \& Bayley, 2007; Dameron \& Durand, 2017; Willmott, 2011).

0 universo do ensino e da pesquisa em gestão caracteriza-se, entre outros aspectos, pelos rankings anuais, nacionais e internacionais das mais diversas instituições (Shangai, Times, Financial Times etc.), baseados na obtenção de credenciamentos internacionais (AACSB, EQUIS, AMBA), pelo número de publicações de pesquisadores que aparecem em revistas classificadas, sendo sempre as estadunidenses as mais bem cotadas, bem como pela hegemonia crescente da língua inglesa no campo que ela influencia (Chanlat, 2014 a, b, c; Collectif, 2019; Dameron \& Durand, 2017; Lussier \& Chanlat, 2017; Nygaard, 2019; Tietze \& Dick, 2012; Tsuda, 2013). À medida que tais classificações bibliométricas são cada vez mais criticadas (Berry, 2009; Willmott, 2011; Tourish \& Willmott, 2015), algumas instituições não hesitam em abandoná-las, tal como acaba de fazer na França a seção de "Gestão y Economia" do CNRS, (o organismo publico mais importante de pesquisa científica na França) suprimindo definitivamente essas classificações.

Não obstante, para os países não anglófonos essa tensão ainda persiste com bastante força, fazendo com que eles oscilem entre adotar uma estratégia dita "internacional", que quase sempre se confunde com o "tudo em inglês" e que leva, portanto, a uma anglicização crescente de espíritos (Bousseba \& Tienari, 2019; Chanlat, 2014 a, b, c; Jackson \& Primecz, 2019; Tietze \& Dick, 2012), e uma estratégia que visa a conservar a pertinência de sua importância local, regional e nacional, evitando ao máximo o encerramento sobre si próprios.

Nos casos dos países latino-americanos e, particularmente, do Brasil, essas questões são, tal como vimos aqui, um objeto recorrente de inúmeros debates no seio da comunidade científica (Alcadipani \& Caldas, 2012; Alcadipani \& Faria, 2014; Bertero, Caldas, \& Wood, 1999; Guedes \& Faria, 2010; Ibarra-Colado, Faria \& Guedes, 2010; Ibarra-Colado, 2006; Paula et al., 2010; Serva, 2017). Perante a atual situação, se alguns parecem sucumbir às regras dominantes, outros, no entanto, tentam oferecer alguma resistência. No Brasil, essa resistência passa por uma crítica das lógicas dominantes (Bertero et al., 2013; Fischer, Waiandt, \& Fonseca, 2011), dos sistemas de classificação (Fischer, 2018; Serva, 2017), da política anglicizante em matéria de publicação (Alves \& Pozzebon, 2013; Gantman, Yousfi, \& Alcadipani, 2015; Serva, 2017 b; Fischer, 2018), e pela afirmação de suas singularidades (Motta, 1983, 2002; Motta \& Caldas,1997; Fachin, 2006, 2014; Davel, Vergara \& Ghadiri, 2007; Waiandt, 2009, 2018) e um questionamento dos trabalhos feitos nos países do Sul a partir de uma reflexão pós-colonial e de uma situação social profundamente desigual (Alcadipani, 2010b; Alcadipani \& Faria, 2014; Alcadipani \& Rosa, 2011; Gantman et al., 2015; Ferreira de Souza, 2018; IBGE, 2020).

Tais críticas defendem, com efeito, uma revisão do sistema como um todo: 
...Portanto, frente ao poderio imperial do reocidentalismo e a obrigação de assumirmos responsabilidades geoepistêmicas mais substantivas, um dos principais desafios para as próximas décadas no Brasil é reconstruir ou reformar as instituições vigentes (Anpad, Capes, CNPq etc.) ... Dessa forma, a área de Gestão no Brasil estará em condições de liderar transformações de mesma ordem que instituições no exterior (US Academy of Management, Chinese Academy of Management, Banco Mundial, Egos etc.) por meio de um grande projeto que abraça a geopolítica do conhecimento, promove a substituição do universalismo eurocêntrico pela pluriversalidade e possibilita a construção de um mundo no qual diversos mundos e conhecimentos coexistem. Talvez seja pedir ou esperar demais da área de Gestão, mas também pode ser uma excelente oportunidade para reinventarmos a área. (Bertero et al., 2013, p. 190)

Elas constituem um sinal de alerta contra uma avaliação tão somente bibliométrica da pesquisa que, em sua ampla maioria, se destina a publicações em língua inglesa e contribui para o embotamento da criatividade:

Temos que tomar muito cuidado para que os valores e métricas que nos regulam não se tornem a castração que não merecemos e acabem com esforços criativos e inovadores. Então, a principal questão é: qual é o impacto que minha gestão tem sobre pessoas, territórios, organizações? É necessário avaliar pelo impacto, pelo que se agrega, evitando-se o quase autismo que encontramos em pessoas que se isolam ao se orientarem por métricas. Aliás, essas métricas podem não valer mais, daqui há alguns poucos anos. É melhor estarmos mais alertas agora e a área se reposicionar. (Fischer, 2018, p. 26)

No Brasil, a agência reguladora CAPES instituiu seu próprio ranking de periódicos, o Qualis. Ele é a referência principal para a avaliação dos Programas de Pós-Graduação, a partir das publicações do corpo docente dos Programas nas revistas mais bem posicionadas no ranking. A arquitetura de valoração do Qualis espelha o leque de index e fatores de impacto das empresas acima citadas. Na área de administração, no estrato superior (A1) do Qualis não figura nenhuma revista brasileira; a grande maioria são periódicos americanos, sendo a língua inglesa totalmente predominante. (Serva, 2017b, p. 55)

Por fim, elas reafirmam a importância do diálogo com outros campos do conhecimento, e reforçam as cooperações internacionais de modo a fazer frente aos enormes desafios que se interpõem em nossas sociedades e no mundo (Alcadipani \& Faria, 2014; Chanlat, Fachin, \& Fischer, 2006, 2007; Eynaud \& França, 2019). Para nós, esse é o caminho que o diálogo entre pesquisadores de língua francesa e pesquisadores brasileiros deve trilhar.

É nesse contexto, como acabamos de ver, que as obras em língua francesa encontram algum respaldo na comunidade brasileira já há algumas décadas, sobretudo por meio de algumas obras e correntes de destaque. Esse interesse baseia-se em um valor histórico e em uma proximidade cultural latina que, a despeito das diferenças entre os próprios países latinos, neste caso em específico, os franceses e brasileiros ainda conservam (Pinot de Villechenon, 2003; Villechenon, Chanlat, \& Rizzo, 2021; Rouquié, 1987).

Esse diálogo, a meu ver, só poderá perdurar se os pesquisadores de língua francesa, bem como os pesquisadores brasileiros, continuarem a defender suas especificidades, a redigir, em sua língua materna, livros, artigos, monografias, e a organizar colóquios e seminários onde questões próprias às suas sociedades sejam levadas 
em consideração (Chanlat, 2014a; 2014b); é um desejo que pesquisadores e pesquisadoras possam continuar a se concentrar em seu ambiente socioeconômico de maneira pertinente (Fischer, 2018). Urge, portanto, evitar emaranhar-se na situação daquele pesquisador norueguês que se confessava incapaz de apresentar o resultado de seus estudos a seus concidadãos na Noruega, em virtude da política do "tudo em inglês" implementada por sua instituição, responsável, em última instância, por the tolher essa capacidade comunicativa (Nygaard, 2019).

De minha parte, como acabo de sublinhar, sempre tentei, ao longo de todos estes anos, ser um autor que afirma as singularidades locais, regionais e nacionais, em todos os espaços onde pude intervir (ensino, pesquisa, publicações, associações científicas nacionais e internacionais), desde sempre apegado a um verdadeiro diálogo intercultural (Chanlat, 2014b; Chanlat, Davel, \& Dupuis, 2013; Chanlat \& Pierre, 2018; Davel, Dupuis \& Chanlat, 2008) entre universos linguísticos, e permanecer atento a essa relação com a comunidade brasileira que me é cara pelas razões mencionadas anteriormente e que possui, a meu ver, apesar dos comentários anteriores, todos os elementos de um campo científico que aspira a uma relativa autonomia (o número, as revistas, as editoras, as associações científicas, os congressos etc.) (Chanlat, 2015). Foi justamente por essa razão que incentivei, o mais que pude, inúmeros colegas, sobretudo aqueles de língua francesa, a participarem dos eventos no Brasil, e inúmeros colegas brasileiros a participarem de eventos de língua francesa; e que, além disso, tentei difundir alguns de seus trabalhos em francês, incluídos aqui na coleção que dirijo na editora da Universidade Laval (Cavalcanti, 2011).

Esse espírito de abertura assenta-se, entre outras coisas, em um certo multilinguismo e numa política ativa em matéria de tradução que nos permitam ter acesso a pensamentos estrangeiros (Iniciativa de Helsínquia, 2019). Muitas vezes, esse não é o caso de nossos colegas estadunidenses, cujo monolinguismo e as escassas traduções de nossos trabalhos de referência em inglês levam-nos, muito frequentemente, a um provincianismo acadêmico, tal como afirma Gaylord Georges Candler (2014) acerca da recepção do pensamento de Guerreiro Ramos nos Estados Unidos. Esse provincianismo, que fique claro, não é um atributo exclusivo de nossos colegas estadunidenses. Os pesquisadores brasileiros, que majoritariamente dominam vários idiomas, estão, portanto, em uma boa situação a fim de evitar essa armadilha sempre que o multilinguismo é utilizado para desenvolver seus trabalhos originais sobre sua realidade, dialogando com outros universos linguísticos com o devido conhecimento de causa (Bertero et al., 2013; Chanlat, 2014a, 2015; Clegg \& Bayley, 2007), e concretizar, assim, 0 pensamento de Guerreiro Ramos (1981/1989, p.5): "Somente através da livre experiência da realidade e sua precisa articulação é que a racionalidade substantiva poderá ser compreendida".

À ocasião desta edição especial, gostaria de concluir este artigo com um desejo aspirado no seguinte sentido: que as relações entre pesquisadores brasileiros e francófonos se mantenham e se desenvolvam por intermédio de uma reciprocidade benevolente, tal como desejava Guerreiro Ramos (1984). Isso se concretizará por meio da constante presença de trabalhos publicados nas diferentes revistas e em nossas diversas editoras e, não menos importante, nesta revista de referência multilíngue que a RAE-Revista de Administração de Empresas se tornou (Tonelli, 2018), a quem desejo, nesta ocasião, todos os meus mais sinceros votos para que ela prossiga nesta formidável aventura que começou há 60 anos. Sessenta anos é, de fato, um aniversário inesquecível para uma revista científica no campo das Ciências Administrativas. *

*A título de comparação, a revista estadunidense Administrative Science Quarterly foi fundada em 1956, apenas cinco anos antes. 


\section{NOTA DO AUTOR}

Professor emérito, Université Paris-Dauphine P.S.L, Dauphine Recherches en Management, Paris, França. Professor convidado, Institut Mines-Télécom Business School, Paris, França.

Professor afiliado, HEC-Montréal, Département de Management, Montréal, Canadá.

\section{REFERÊNCIAS}

Aerosa, J. (2019). O mundo do trabalho em (re)análise: Um olhar a partir da psicodinâmica do trabalho. Laboreal, 15(2), 1-24. doi: $10.4000 /$ laboreal.15504

Aglietta, M. (1997). Régulation et crises du capitalisme. Paris, France: Odile Jacob.

Aktouf, O. (1996). A administração entre tradição e a renovação. São Paulo, SP: Casa Editorial Atlas.

Alcadipani, R. (2010a). Critical international management and international critical management: Perspectives from Latin America. Critical Perspectives on International Business, 6, (2/3), 86-96. doi: 10.1108/cpoib.2010.29006baa.001

Alcadipani, R. (2010b). From Latin America to the world: Notes on the (possible) latin american management styles. In A. Guedes, \& A. Faria (Eds.), International management and international relations: A critical perspective from Latin America (Vol. 1, pp. 136-158). New York, USA: Routledge.

Alcadipani, R., \& Bertero, C. (2012). Guerra Fria e ensino do management no Brasil: 0 caso da FGV/EAESP. RAE-Revista de Administração de Empresas, 52(3), 284-299. doi: 10.1590/ So034-75902012000300002

Alacadipani, R., \& Bertero, C. O. (2014l). Uma escola NorteAmericana Ultramar? Uma historiagrafia da EAESP. RAERevista de Administração de Empresas, 54(2), 154-169. doi: /10.1590/So034-759020140204

Alcadipani, R., \& Caldas, M. (2012). Americanizing Brazilian management. Critical Perspectives on International Business, 8(1), 37-55. doi: 10.1108/17422041211197558

Alcadipani, R., \& Cooke, B. (2013). The Ford Foundation's mess in Brazil. Best Paper Proceedings of the Academy of Management Meeting. doi: 10.5465/ambpp.2013.218

Alcadipani, E., \& Faria, A. (2014). Fighting Latin American marginality in "International business". Critical Perspectives on International Business, 10(1/2), 107-111. doi: 10.1108/ cpoib-11-2013-0047

Alcadipani, R., \& Rosa, A. R. (2011). From global management to glocal management: Latin American perspectives as a counter-dominant management epistemology. Canadian Journal of Administrative Science, 28(4), 453-466. doi. org/10.1002/cjas.165

Alter, N. (2002). L'innovation ordinaire. Paris, France: PUF.

Alter, N. (2010). Donner et prendre: La coopération en entreprise. Paris, France: La Découverte.
Alves, M. A., \& Pozzebon, M. (2013). How to resist linguistic domination and promote knowledge diversity. RAE-Revista de Administração de Empresas, 53(6), 629-633. doi: 10.159o/ So034-759020130610

Amado, G. (2013). Les processus psychiques au sein des groupes de travail: au-delà de Bion et de Pichon-Rivière. Nouvelle Revue de Psychosociologie, 1(15), 163-182. Recuperado de https:// www.cairn.info/revue-nouvelle-revue-de-psychosociologie2013-1-page-163.htm

Amblard, H., Bernoux, P., Herreros, G., \& Livian, Y.-F. (1995). Les nouvelles approches en sociologie des organisations. Paris, France: Seuil.

Andion, M.-C. (1998). Gestão em organizações da economia solidária: Contornos de uma problemática. Revista de Administração Pública, 32(1), 7-25. Recuperado de http:// bibliotecadigital.fgv.br/ojs/index.php/rap/article/ view $/ 7680$

Andion, M.-C. (2005). A gestão no campo da economia solidária: Particularidades e desafios. Revista de Administração Contemporânea, 9, 79-99. doi: 10.1590/S141565552005000100005

Andion, C., \& Serva, M. A. (2006). Etnografia e os estudos organizacionais. In K, C, Godoi., R, Bandeira-de-Mello, \& A., Barbosa da Silva. (Orgs.), Pesquisa qualitativa em estudos organizacionais: Paradigmas, estratégias e métodos. São Paulo, SP: Saraiva.

Araújo, N. G. de, \& Barros, V. A. de. (2019). A psicologia do trabalho e as clínicas do trabalho no Brasil. Laboreal, 15(2), 1-12. doi: 10.400o/laboreal.15515

Aubert, N., \& Gauléjac, V. de. (1993). Coste de la excelencia ${ }_{i}$. Madrid, España: Paidos.

Audet, M., \& Déry, R. (1996). La science réfléchie: Quelques empreintes de l'épistémologie des sciences de l'administration. Anthropologie et Sociétés, 20, 1, 103-123. doi : 10.7202/015397

Audet, M., \& Malouin, J.-L. (Orgs.). (1986). La production des connaissances scientifiques de l'administration. Québec, Canada: Les Presses de l'Université Laval.

Azevedo, A., \& Albernaz, R. (2006). A "antropologia” do guerreiro: A história do conceito de homem parentético. Em memória a Eliana Guerreiro Ramos (1949-2003). Cadernos EBAPE.BR, 4(3), 1-19. Recuperado de http://bibliotecadigital. fgv.br/ojs/index.php/cadernosebape/article/view/7398 
Barreto, O. (1999). Escola de Administração da UFBA: 40 anos de história. Organizações e Sociedade, 6(15), 9-14. doi: 10.1590/ S1984-92301999000200001

Barros, A., Alcadipani, R., \& Bertero, C. O. (2018). A criação do curso superior em administração na ufrgs em 1963: uma análise histórica [The creation of the higher education course in administration at UFRGS in 1963: A historical analysis]. RAE-Revista de Administração de Empresas, 58(1), 3-15. doi: 10.159o/s0034-759020180102

Bartel-Radic, A. (2013). 'Estrangeirismo' and flexibility: intercultural learning in Brazilian. MNCs. Management International/International Management/ Gestión International, 17(4), 239-253. doi: 10.7202/1020680

Barus-Michel, J., Enriquez, E., \& Lévy, A. (Dir.). (2002). Vocabulaire de Psychosociologie. Ramonville Saint-Agne, France: Éditions Érès

Bayart, D., Borzeix, A., \& Dumez, H. (Dir.), (2010). Langage et organisations: Sur les traces de Jacques Girin. Palaiseau, France: Presses de l’École Polytechnique.

Bélanger, P., \& Lévesque, B. (1996). La modernisation sociale des entreprises. Montréal, Canada: Presses de l'Université de Montréal.

Bendassolli, P., \& Borges-Andrade, J. (Orgs.). (2015). Dicionário de psicologia do trabalho e das organizações. São Paulo, SP: Artesa.

Bendassolli, P., \& Soboll, L. A. P. (Orgs.). (2011/2021). Clínicas do trabalho, novas perspectivas para compreender do trabalho na atualidade. São Paulo, SP: Atlas.

Bernoux, P (1985). Sociologie des organisations. Paris, France: Seuil.

Berry, M. (1983). La technologie invisible. Paris, France: Ecole Polytechnique.

Berry, M. (2009). Les mirages de la bibliométrie, ou comment scléroser la recherche en croyant bien faire. Revue du MAUSS, 1(33), 227-245. Recuperado de https://www.cairn.info/revuedu-mauss-2009-1-page-227.htm

Berry, M. (2011). Savoirs théoriques et gestion. In J.-M. Barbier (Dir.), Savoirs théoriques et savoirs d'action (pp. 43-56). Paris, France: Presses Universitaires de France.

Bertero, C. O. (2006). Ensino e pesquisa em administração. São Paulo, SP: Thomson Learning.

Bertero, C. O., Alcadipani, R., Cabral, S., Faria, A., \& Rossoni, P. (2013). Os desafios da produção de conhecimento em administração no Brasil. Cadernos EBAPE.BR, 11(1), 181-196. doi: 10.1590/S1679-39512013000100012

Bertero, C. O., Caldas, M. P., \& Wood, T., Jr. (1999). Produção científica em administração: Provocações, insinuações e contribuições para o debate local. Revista de Administração Contemporânea, 3(1), 147-178. doi: 10.1590/S1415 65551999000100009

Bertero, C. O., Caldas, P. P., \& Wood, T. (Coord.). (2005). Produção científica em administração no Brasil: $O$ estado-da-arte. São Paulo, SP: Atlas.
Bessy, C., \& Favereau, 0. (2003). Institutions et économie des conventions. Cahiers d'Économie Politique, 1(44), 119164. doi: 10.3917/cep.044.0119

Betiol, M. I. S., \& Tonelli, M. J. (2002). A Trama drama numa intervenção: Análise sobra oticada psicodinâmica do trabalho. Organizações \& Sociedade, 9(24), 11-23. doi: 10.1590/S198492302002000200001

Boltanski, L., \& Chiapello, E. (1999). Le nouvel esprit du capitalisme. Paris, France: Gallimard.

Boltanski, L., \& Thévenot, L. (1991). De la justification: Les économies de la grandeur. Paris, France: Gallimard.

Bonnafous, E. (1953). Les liens intellectuels entre la France et l'Amérique latine. Revue Des Deux Mondes (1829-1971), 6386. Recuperado de http://www.jstor.org/stable/44585861

Boussebaa, M., \& Tienari, J. (2019). Englishization and the politics of knowledge production in management studies. Journal of Management Inquiry, 30(1), 59-67. doi: 10.1177/1056492619835314

Bouville, G., \& Yousfi, H. (Dir.). (2021). Les dimensions oubliées de la gestion, anthropologie, management, travail et organisation: Mélanges en l'honneur du professeur JeanFrançois Chanlat. Ste-Foy, Québec, Canada: Les Presses de I'Université Laval; Paris, France: Hermann.

Boyer, R., \& Cohen, P. (2010). Teoria da regulação: Os fundamentos. São Paulo: Estação Liberdade

Buarque de Holanda, S. (1936). Raízes do Brasil. Rio do Janeiro: Editora José Olympio Editora. Edição francesa, (1998) Racines du Brésil, Paris: UNESCO/Gallimard.

Bueno, J. M., \& Freitas, M. E. (2016). Les équipes multiculturelles dans les filiales brésiliennes de multinationales. In J.-P. Dupuis, J.-P. Lemaire, \& E. Milliot (Coord.), Ancrages culturels dans un monde en mutation (pp. 157-172). Paris, France: vuibert.

Caldas, M., Fachin, R., \& Fischer, T. (1999). Prefácio à edição brasileira do Handbook de Estudos Organizacionais. Vol.1: Modelos de Análise e Novas Questões em Estudos Organizacionais. (Eds), Clegg, S., Hardy, C., \& Nord, W. São Paulo, SP: Atlas, 61-98.

Caldas, M. P., \& Wood, T., Jr. (1997). For the English to see': The importation of managerial technology in late 2oth-century Brazil. Organization, 4(4), 517-534. doi: 10.1177/135050849700400410

Calvacanti, B. (2011). Le leadership dans les organisations publiques au Brésil. Ste-Foy, Québec, Canada: Les Presses de l'Université Laval.

Candler, G. G. (2014). Linguistic diglossia and parochialism in American public administration: The missing half of Guerreiro Ramos's redução sociológica.Administrative Theoryand Praxis, 28(4), 540-561. doi: 10.1080/10841806.2006.11029561

Cassundé, F. R., Barbosa, M. A. C., \& Mendonça, J. R. C. de. (2016). A influência da tradição anglo-saxônicas estudos organizacionais brasileiros: 0 que mudou (ou não) nos últimos 15 anos? Perspectivas em Gestão \& Conhecimento, 6(1), 238-254. Recuperado de https://periodicos.ufpb.br/ ojs2/index.php/pgc/article/view/27064 
Castaingts-Teillery, J. (2014). La crisis financiera. Un análisis de etnoeconomía. Conferencia, Academia Mexicana de Economía Política, Ciudad de México, México. Recuperado de amepmexico.com.mx.

Chanlat, A., \& Dufour, M (dir) (1985). La rupture entre l'entreprise et les hommes. Montréal, Québec, Canada: Québec/ Amériques.

Chanlat, J.-F. (Dir.). (1992a). Indivíduo na organização: Dimensões esquecidas (Vol. I). São Paulo, SP: Publicação Atlas, Montréal, Québec, Canada: HEC CETAI.

Chanlat J.-F. (1992b). L'analyse des organisations: Un regard sur les productions de langue française contemporaines (19501990). Cahiers De Recherche Sociologique, (18-19), 93-138. doi: 10.7202/1002305ar

Chanlat, J.-F. (Dir.). (1994a). O indivíduo na organização: Dimensões esquecidas (Vol. II). São Paulo, SP: Publicação Atlas, Montréal, Québec, Canada: HEC-CETAI.

Chanlat, J.-F. (1994b). Francophone organizational analysis (1950-1990): An overview. Organization Studies, 15(1), 47-79. doi: 10.1177/017084069401500103

Chanlat, J.-F. (Dir.). (1996). O indivíduo na organização: Dimensões esquecidas (Vol. III), São Paulo, SP: Publicação Atlas, Montréal, Québec, Canada: HEC CETAI.

Chanlat J.-F. (2000). Ciências sociais e administração. São Paulo, SP: Publicação Atlas.

Chanlat, J.-F. (2010a). Gestão das empresas: Uma perspectiva antropológica. (Coleção Debates em Administração). São Paulo, SP: Cengage Learning.

Chanlat, J.-F. (2010b). Hommage à José Roberto Gomes da Silva. Revue Française de Gestion, 36(20), 183-184. Recuperado de https://www.cairn.info/revue-francaise-de-gestion-20104-page-183.htm

Chanlat, J.-F. (2014a). Langue et pensée dans la recherche en gestion: Constats, enjeux et atouts de la langue française. Gérer et Comprendre, 115(1), 4-17. doi: 10.3917/geco.115.0004

Chanlat, J.-F. (2014b). A língua e o pensar no campo da pesquisa em administração: Constatações e questões para os pesquisadores que não utilizam a língua inglesa. RAE-Revista de Administração de Empresas, 54(6), 706-714. doi: 10.159o/ So034-759020140610

Chanlat, J.-F. (2014C). Language and thinking in organization studies: The visibility of French OS production in the AngloSaxon OS field. International Journal of Organizational Analysis, 22 (4), 504-533. doi: 10.1108/IJOA-09-2013-0708

Chanlat J.-F. (2015). Le champ des études organisationnelles: Le regard critique d'un chercheur plurilingue. RAE- Revista de Administração de Empresas, 55(2), 226-230. doi: 10.1590/ So034-759020150212

Chanlat, J-F. (2020). La catastrophe sanitaire actuelle: un fait social total. Le Libellio d'AEGIS, 16(7), p. 3-30. Recuperado de https://hal.archives-ouvertes.fr/hal-03120567

Chanlat, J.-F, Davel, E., \& Dupuis, J.-P. (2013). Cross-Cultural Management. Culture and management across the world. Londres, RU: Routledge.
Chanlat, J.-F, Dameron, S., Dupuis, J.-P., Freitas, M,E, \& Özbilgin, M. (2013). Management et Diversité : lignes de tension et perspectives. Management international / International Management / Gestiòn Internacional, 17, 5-13. doi: 10.7202/1015807ar

Chanlat, J.-F., Özbilgin, M. (2018). Management et diversité: Comparaisons internationales. Ste-Foy, Québec, Canada: Les Presses de l'Université Laval, Paris, France: Hermann.

Chanlat, J.-F., Özbilgin, M. (2018). Management et diversité: approches thématiques et défis sociopolitiques. Ste-Foy, Québec, Canada: Les Presses de l'Université Laval, Paris, France: Hermann.

Chanlat, J.-F., Pierre, P.(2018). Management interculturel. Evolution, tendances et critiques. Caen, France: EMS.

Chanlat, J.-F., Fachin, R., \& Fischer, T. (Dir.). (2006). Analyse das organizações: Perspectivas latinas (Vol. 1). Porto Alegre, Brasil: UFRGS

Chanlat, J.-F., Fachin, R., \& Fischer, T. (Dir.). (2007). Analyse das organizações: Perspectivas latinas (Vol. 1). Porto Alegre, RS: UFRGS

Chanlat, J-F.,\& Séguin, F. (1987). L'analyse des organisations. Tome II: les composantes de l'organisation, Montréal, Québec, Canada: Gaëtan Morin.

Cicero, A. F. C., Cardoso, J. M. M., \& Klipan, M. L. (2019). Panorama da psicodinâmica do trabalho no Brasil entre os anos de 2005 e 2015. Revista Interinstitucional de Psicologia, 12(1), 19-36. doi: $10.36298 /$ gerais2019120103

Clarke, T., O'Brien, J., \& O'Kelley, C. (2019). The Oxford Handbook of The Corporation. Oxford, UK: Oxford University Press.

Clegg, SR., \& Bayley, J.R. (Eds). (2007). International Encyclopedia of Organization studies. Thousand. Oaks: Sage.

Clegg, S., Hardy C., \& Nord, W. (Ed.). (1999). Handbook de Estudos Organizacionais: Modelos de Análise e Novas Questões em Estudos Organizacionais (Vol.1). São Paulo, SP: Atlas.

Clegg, S., Hardy C., \& Nord, W. (Ed.). (2001). Handbook de Estudos Organizacionais: Reflexões e Novas Direções (Vol.2). São Paulo, SP: Atlas.

Clegg, S., Hardy C., \& Nord, W. (Ed.). (2004). Handbook de Estudos Organizacionais: Ação e Análise Organizacionais. (Vol. 3), São Paulo, SP: Atlas.

Clot, Y. (2010). Trabalho e poder de agir. Belo Horizonte, MG: Fabrefactum.

Clot, Y., \& Lhuillier, D. (2006). Perspectives en cliniques $d u$ travail. Toulouse, France: Erès.

Clot, Y., \& Lhuillier, D. (2010). Agir en clinique du travail. Toulouse, France: Erès.

Collectif. (2019, Février). La recherche francophone en sciences de gestion n'a aucune raison d'acccepter une soumission à un ordre anglo-saxon. Le Monde, 20. Recuperado de https://www. lemonde.fr/idees/article/2019/02/20/la-recherche-francophone-en-sciences-de-gestion-n-a-aucune-raison-d-accepterune-soumission-a-un-ordre-anglo-saxon_5425600_3232.html 
Coriat, B. (1994). Pensar pelo avesso. Rio de Janeiro, RJ: UFRJ/ Revan.

Crozier, M. (1963a). Subdesenvolvimento, administração e burocracia. RAE-Revista de Administração de Empresas, 3(9), 117-134. Recuperado de http://bibliotecadigital.fgv.br/ojs/ index.php/rae/article/view/41005

Crozier, M. (1963b). Le phénomène bureaucratique. Paris, France: Seuil.

Crozier, M. (1981). O fenômeno burocrático: Ensaio sobre as tendências burocráticas dos sistemas de organização modernos e suas relações na França, com o sistema social e cultural (Vol. 2.). (. A. Gil Sobrinho, Trad.). Brasília, DF: Editora Universidade de Brasília.

Crozier, M. (2000). À quoi sert la sociologie des organisations? Paris, France: Arslan.

Crozier, M., \& Friedberg, E. (1977). L'acteur et le système. Paris, France: Seuil.

Dameron, S., Durand, T. (Eds). (2017). The Future of Management Education. Volume 1: Challenges facing Business Schools around the World. London, UK: Palgrave.

Davel, E., Dantas, M., \& Vergara, S. C. (2008). Culture et gestion au Brésil. In E. Davel, J.-P. Dupuis, \& J.-F. Chanlat (Eds.), Gestion en contexte interculturel. Québec, Canada: Presses de l'Université de Laval et Téléuniversité. CD.

Davel, E., \& Dupuis, J.-P., \& Chanlat, J.-F. (Eds.). (2008). Gestion en contexte interculturel. Québec, Canada: Presses de l'Université de Laval et Téléuniversité.

Davel, E., \& Vergara, S, C. (Orgs.). (2001). Gestão com pessoas e subjetividade. São Paulo, SP: Atlas.

Davel, E., Vergara, S., \& Ghadiri, S. (Orgs.). (2007). Administração com arte: Experiências vividas de ensino-aprendizagem. São Paulo, SP: Atlas.

Davel, E. P. B., \& Melo, M. C. de O. L. (2005). Gerência em ação: Singularidades e dilemas do trabalho gerencial. Rio de Janeiro, RJ: Editora FGV.

David, A., Hatchuel, A., \& Laufer, R. (2012). Les nouvelles fondation des sciences de gestion. Paris, France: Presses des Mines.

Dejours, C. (1996). Uma nova visão do sofrimento humano nas organizações. In J.-F. Chanlat (Dir.), $O$ indivíduo na organização: Dimensões esquecidas. (Vol 1). São Paulo, SP: Editora Atlas, 149-174.

Dejours, C. (2007). Fator humano. São Paulo, SP: Editora Atlas.

Dejours, C. (2011). A banalização da injustiça social. São Paulo, SP: Editora Atlas.

Dejours, C. (2015). A loucura do trabalho: Estudo de psicopatologia do trabalho. São Paulo, SP: Cortez EditoraOboré.

Dejours, C. (2017). Psicodinâmica do trabalho: Casos clínicos. São Paulo, SP: Dublinense.

Dejours, C., Abdoucheli, E., \& Jayet, C. (1994). Psicodinâmica do trabalho. São Paulo, SP: Atlas.
d'Iribarne, P., Chevrier, S., Henry, A., Segal, J.-P., \& Tréguer-Felten, $\mathrm{G}$. (2020). Cross-cultural management revisited: A qualitative approach. Oxford, UK: Oxford University Press.

d'Iribarne, P., Henry, A., Segal, J.-P., Chevrier, S., \& Globokar, T. (1998). Cultures et mondialisation: Gérer par-delà les frontières. Paris, France: Seuil.

Dufour, M.,Chanlat,A.(1985). La rupture entre l'entreprise et les hommes. Montréal, Québec, Canada: Québec/Amériques.

Dumez, H. (2016). Méthodologie qualitative: Les questions clés de la démarche compréhensive. Paris, France: Vuibert.

Dupuis, J.-P., \& Kuzminski, A. (1998). Sociologie de l'économie, du travail et de l'entreprise. Montréal, Canada: Gaëtan Morin éditeur.

Enriquez, E. (1990). Da horda ao estado: Psicanálise do vínculo social. São Paulo, SP: Editora Senac.

Enriquez, E. (1997). A organização em análise. Capa comun. Kindle Direct Publishing.

Enriquez, E. (2007). As figuras do poder. Capa Comun, Kindle Direct Publishing.

Enriquez, E. (2014). Jogos de poder na empresa: Sobre os processos de poder e estrutura. São Paulo, SP: Zagodoni Editora.

Entreprises et Histoire. (2016). Cinquante ans de sociologie des organisations. [Numéro spécial], 3(84). Paris, FR: ESKA

Etzioni, A. (1967). Organizações complexas. São Paulo, SP: Pioneira.

Eymard-Duvernay, F. (2004). Economie politique de l'entreprise. Paris, France: La découverte

Eynaud, P., \& França, C. de., Filho. (2019). Solidariedade e organizações: Pensar uma outra gestão. São Paulo, SP: Ateliê de Humanidades Editorial. [Edition française, Solidarité et organisation: Penser une autre gestion. Toulouse, France: Erès.

Fachin, R. (2006). Construindo uma associação científica: Trinta anos da ANPAD - Memórias, registros, desafios. Porto Alegre, RS: ANPAD.

Fachin, R. (2014). Memórias e posicionamentos em estudos organizacionais. Revista Brasileira de Estudos Organizacionais, 1(1), 4-16. doi: 10.21583/2447-4851.rbeo.2014.v1n1.27V

Fachin, R., \& Cavedon, N. R. (2003). Em busca da especificidade da influência francesa na análise organizacional no Brasil. Cadernos EBAPE.BR, 1(1), 1-13. doi: 10.1590/S167939512003000100006

Favereau, 0. (1989). Organisation et marché. Revue française d'économie, 4(1), 65-96. doi: 10.3406/rfeco.1989.1203

Ferreira de Souza, P, H, D. (2018). Uma história de desigualdade: a concentração de renda entre os ricos no Brasil, 1926-2013. São Paulo, SP: Hucitec.

Fischer, T., \& Davel, E. (2018). Administração como aprendizagem: do vir ao porvir com Tânia Fischer. Farol . Revista de Estudos Organizacionais e Sociedade, 5(12), 13-31. Recuperado de https://revistas.face.ufmg.br/index.php/ farol/article/view/4794 
Fischer, T., Caldas, M., \& Fachin, R. (Orgs.). (2004a). Handbook de estudos organizacionais: Ação e análises organizacionais (Vol. 2). São Paulo, SP: Editora Atlas.

Fischer, T., Caldas, M., \& Fachin, R. (Orgs.). (2004b). Handbook de estudos organizacionais: Ação e análises organizacionais (Vol. 3). São Paulo, SP: Editora Atlas.

Fischer, T., Waiandt, C., \& Fonseca, R. L. (2011). A história do ensino em administração: Contribuições teóricometodológicas e uma proposta de agenda de pesquisa. Revista de Administração Pública, 45(4), 911-939. doi: 10.1590/So034-76122011000400002

Fischer, T. M. (1985). 0 ensino de administração pública no Brasil: Da tutela estrangeira à autonomia necessária. In Reunião Nacional da ANPAD (pp165-170). Anais... Florianópolis: Ed. UFSC

França, G, C. dé, Filho, Laville, J.-L., Medeiros, A. J. de S., \& Magnen, J.-L. (2005). Ação pública e economia solidária: Uma perspectiva internacional. Salvador, Bahia: Editora CIAGS/ UFBA.

Freitas, M. E. (1991). Cultura organizacional: Grandes temas em debates. RAE-Revista de Administração de Empresas, 31(3), 73-82. Recuperado de http://bibliotecadigital.fgv.br/ojs/ index.php/rae/article/view/38605

Freitas, M. E. de. (1999a). Cultura organizacional: Formação, tipologias e impacto. São Paulo, SP: Editora Atlas.

Freitas, M. E. de. (1999b). Cultura organizacional: Identidade, sedução e carisma? Rio de Janeiro, RJ: FGV.

Freitas, M. E. de. (2001). Assédio moral e assédio sexual: faces do poder perverso nas organizações. RAE-Revista de Administração de Empresas, 41(2), 8-19. doi: 10.1590/So03475902001000200002

Freitas, M. E. de. (2008b). Entrevista com Jean-François Chanlat. GVexecutivo 7(11), 62-69. doi: 10.12660/gvexec. v7n1.2008.34087

Freitas, M.-E. de. (2018). Gérer la diversité au Brésil. In J.F. Chanlat, \& Özbilgin, M, (Dir.), Management et diversité: Comparaisons internationales (pp.115-162). Ste-Foy, Québec, Canada: Les Presses de l'Université Laval; Paris, France: Hermann.

Freitas, M. E. de, \& Dantas, M. (2011). Diversidade sexual e trabalho. São Paulo, SP: Cengage.

Freitas, M. E. de, \& Dantas, M. (2014). L'étranger dans le groupe: Pont et porte de l'interculturel. In A.-M. Guénette, E. Mutabazi, S. Von O. Ottino, \& P. Pierre (Dir.), Management interculturel, altérité et identités (pp. 523-531). Paris, France: L'Harmattan.

Freitas, M. E. de, \& Motta, F. C. P. (2000). Vida psíquica e organização. Rio de Janeiro, RJ: Editora FGV.

Freyre, G. (1963). Casa grande e senzala. Brasília, DF: Ed. UnB.

Gantman, E,. Yousfi, H., \& Alcadipani, R. (2015). Challenging Anglo-Saxon dominance in management and organizational knowledge. RAE-Revista de Administração de Empresas, 55(2), 126-129. doi: 10.1590/So034-759020150202V
Gauléjac, V. De. (2005). Gestão como doença social: Ideologia, poder gerencialista e fragmentação social. São Paulo, SP: Editora Ideias e Letras.

Gaviria, L. G. A., \& Molinier, P. (Éds.). (2011). El trabajo y la ética del cuidado. Bogotá, Colombia: La Carreta Social.

Girin, J. (2016). Langage, organisations, situations et agencements [avec la collaboration de Jean-François Chanlat, Hervé Dumez et Michèle Breton]. St-Foy, Québec, Canada: Presses de l'Université de Laval, Paris, France: Hermann.

Gonzáles-Miranda, D, R., \& Ramirez Martinez, G. (2018). Introducción: los estudiosorganizacionales en Latinoamérica. Una realidad fragmentada en busca de identidad Tratado de estudios organizacionales.(Volumen 1). Teorización sobre el campo, Medellin, Colombia: Editorial EAFIT, Mexico: Universidad Autónoma Metropolitana, Red Mexicana de Investigadores en Estudios Organizacionales, Londres: Sage, 21-40.

Gonzáles-Miranda, D, R., \& Ramirez Martinez, G. (2020). Tratado de estudios organizacionales. Volumen 2. Exploración de las temáticas, Medellin, Columbia: Editorial EAFIT, Mexico: Universidad Autónoma Metropolitana, Red Mexicana de Investigadores en Estudios Organizacionales, London, UK: Sage.

Grange, J. (2000). Auguste Comte: La politique et la science. Paris, France: Éditions Odile Jacob.

Guedes, A., \& Faria, A. (Eds.). (2010). International management and international relations: A critical perspective from Latin America. New York, USA: Routledge.

Harzing, A-W. (2016, June). Do Google Scholar, Scopus and the Web of Science speak your language? EURAM Conference, Paris

Hatchuel, A. (2021, Janvier). La France, pionnière de la bonne gouvernance. Le Monde, 6 . Recuperado de https://www. lemonde.fr/emploi/article/2021/01/06/la-france-pionnierede-la-bonne-gouvernance_6065334_1698637.html

Ibarra-Colado, E. (2006). Organization studies and epistemic coloniality in Latin America: Thinking otherness from the margins. Organization, 13(4), 463-488. doi : $10.1177 / 1350508406065851$

Ibarra-Colado, E., Faria, A., \& Guedes, A. (2010). Introduction to the special issue on "Critical international management and international critical management: Perspectives from LatinAmerica". Critical Perspectives on International Business, 6(2/3), 86-96. doi: 10.1108/17422041011049923

Initiative d'Helsinki. (2019). Initiative d'Helsinki sur le multilinguisme dans la communication savante [Helsinki Initiative on Multilingualism in Scholarly Communication]. Recuperado de https://www.helsinki-initiative.org/fr

Instituto Brasileiro de Geografia e Estatistica. (2019). Sintese de Indicadores Sociais: uma análise das condições de vida da população brasileira. Rio de Janeiro, RJ: IBGE.

Jackson, T, \& Primecz, H. (2019). Cross-cultural management studies and the Englishization of scholarly communication: A paradox. International Journal of Cross Cultural Management, 19(2), 115-119. https://doi. org/10.1177/1470595819865095 
Joly, A, (2004). Fiefs et entreprises en Amérique latine. Ste-Foy, Québec, Canada: Les Presses de l'université Laval.

Kirschner, A.-M., \& Gomes, E. R. (2014a). La sociologie brésilienne et l'entreprise à la fin du XXe siècle. Sociologies Pratiques, 3(3), 41-48. doi : 10.3917/sopr.hs01.0041

Kirschner, A.-M., \& Gomes, E. R. (2014b). Les sciences sociales brésiliennes aujourd'hui: Des questions structurelles aux nouvelles questions sociales. Sociologies Pratiques, 2(2), 123-134. doi: 10.3917/sopr.017.0123

Kury, L. (2003). Nation, races et fétichisme: La religion de l'humanité au Brésil. Revue d'Histoire des Sciences Humaines, 1(1), 125-137. doi: 10.3917/rhsh.008.0125

Lapassade, G. (1989). Grupos, organizações e instituições. Rio de Janeiro, RJ: Francisco Alves

Lapierre,L.(1989). Imaginário, Administração e Liderança. RAERevista de Administração de Empresas, 29(4), 05-16. doi : 10.1590/So034-75901989000400002

Lapierre, L. (2005). Gérir e Criar. RAE-Revista de Administração de Empresas, 45(4), 108-117. doi : 10.1590/So034 75902005000400008

Laufer, R. (1977). Crise de légitimité dans les grandes organisations. Revue Française de Gestion, 9 (1), 112-123.

Laufer, R., \& Paradeise, C. (1982). Le prince bureaucrate: Machiavel au pays du marketing. Paris, France: Flamarion.

Laville, J-L. (dir). (2011). Economie solidaire. Paris, France: Editions CNRS.

Lévesque, B., Bourque, G., \& Forgues, E. (1997, juil/décembre). La sociologie économique de langue française: Originalité et diversité des approches. Cahiers Internationaux de Sociologie, $103,265-294$

Lima, M.-E. A. (1998). A psicopatologia do trabalho: Origens e desenvolvimentos recentes na França. Psicologia, Ciências e Profissão, 18(2), 10-15. doi: 10.1590/s141498931998000200003

Lima, M. E. A. (2013). Saúde mental e trabalho: Limites, desafios, obstáculos e perspectivas. Cadernos de Psicologia Social do Trabalho, 16(spe1), 91-98. doi: 10.11606/issn.1981-0490. v16ispe1p91-98

Lins, I. (1967). História do positivismo no Brasil. São Paulo, SP: Cia. Editora Nacional.

Lourau, R. (1975). A análise institucional. Petrópolis, RJ: Vozes.

Lussier, S., Chanlat, J-F. (2017). Les enseignants en gestion face aux nouvelles injonctions institutionnelles. Une étude FranceQuébec. Revue Française de Gestion, 43(267), 79-96. doi: $10.3166 /$ rfg.2017.00183

Mandiola, M. (2010). Latin America's critical management? A liberation genealogy. Critical Perspectives on International Business, 6(2/3), 162-176. doi: 10.1108/17422041011049978

Martes, A.-C. B., Loureiro, M., Abramovay, S. M., \& Serafim, M. (2007). Apresentação Fórum - Sociologia econômica. RAEeletrônica, 6(1), Art 10. Recuperado de https://www.scielo. $\mathrm{br} / \mathrm{pdf} / \mathrm{raeel} / \mathrm{v6n1/a05v6n1.pdf}$
Martinet, A.-C. (Org.) (1990). Épistémologies et sciences de gestion. Paris, France: Economica.

Martinet, A.-C., \& Pesqueux, Y. (2013). Épistémologie des sciences de gestion. Paris, France: Vuibert.

Melo, M. C. De O.L. (1984). Processos de participação como meios não-instutionalizados dois postulados básicos de regulação de conflitos. RAE-Revista de Administração de Empresas, 24(4), 11-18. doi: 10.1590/So034-75901984000400004

Mello, M, S. B. de, Filho. (2019). Quarenta anos de Escola Francesa da Regulação: Entre o marxismo e o institucionalismo histórico. Economia e Sociedade, 28(1), 25 29. doi: 10.1590/1982-3533.2019v28n1arto2

Merlo, A. C., \& Mendes, A. M. B. (2009). Perspectivas do uso da psicodinâmica do trabalho no Brasil: Teoria, pesquisa e ação. Cadernos de Psicologia Social do Trabalho, 12(2), 141-156. doi: 10.11606/issn.1981-0490.v12i2p141-156

Molinier, P. (2013). O trabalho e a psique: Uma introdução à psicodinâmica do trabalho (F. Soudant, Trad.). Brasília, DF: Paralelo 15.

Motta, F. C. P. (1981). Burocracia e autogestão: A proposta de Proudhon. São Paulo, SP: Brasiliense.

Motta, F. C. P. (1983). A questão da formação do administrador. RAE-Revista de Administração de Empresas, 23(4), 53-55. doi: 10.1590/s0034-75901983000400005

Motta, F. C. P. (1984). Participação e co-gestão: Novas formas de administração. São Paulo, SP: Brasiliense.

Motta, F. C. P. (1988). As formas organizacionais do estado. RAE Revista de Administração de Empresas, 28(4), 15-31. doi: 10.1590/So034-75901988000400003

Motta, F. C. P. (1990). Organização e poder. São Paulo, SP: Atlas.

Motta, F. C. P. (2002). Teoria geral da administração: Uma introdução. São Paulo, SP: Thompson Learning.

Motta, F. C. P. (2003). Teoria das organizações: Evolução e crítica. São Paulo, SP: Thompson Learning.

Motta, F. C. P., Alcadipani, R., \& Bresler, R. (2001). A valorização do estrangeiro como segregação nas organizações. Revista de Administração Contemporânea, 5(Edição Especial), 59-79. doi: $10.1590 / \mathrm{s} 1415-65552001000500004$

Motta, F. C. P., \& Caldas, M. (1997). Cultura organizacional e cultura brasileira. São Paulo, SP: Atlas.

Nugent, P. (1993). Compte rendu de L'individu dans l'organisation: Les dimensions oubliées sous la direction de Jean-François Chanlat, Québec, Canada, Les Presses de l'Université Laval et les Éditions Eska, 1990, 842 p, Revue québécoise de science politique, (24), 186-191.

Nygaard, L. P. (2019). The institutional context of "linguistic injustice": Norwegian social scientists and situated multilingualis. Publications, 7(10), 1-13. Doi: 10.3390/ publications7010010

Orléan, A. (2004). Analyse économique des conventions. Paris, France: Quadrige, PUF. 
Padioleau, J.-G. (1992, Juillet-septembre). Jean-François Clianlat, L'individu dans l'organisation, les dimensions oubliées, 1990. Sociologie du travail, 34ロ année, (3), pp. 384-385.

Pagès, M., Bonetti, M., \& Gauléjac, V. de. (1987). O poder das organizações. São Paulo, SP: Casa Editorial Atlas.

Paula, A. P. P. de. (2007). Guerreiro Ramos: Resgatando o pensamento de um sociólogo crítico das organizações. Organização \& Sociedade, 14(40), 169-188. doi: 10.1590/ S1984-92302007000100010

Paula, A. P. P. de, Maranhão, C. de A., Barreto, R. de O., \& Klechen, C. F. (2010). A tradição e a autonomia dos estudos organizacionais críticos no Brasil. RAE-Revista de Administração de Empresas, 50(1), 10-23. doi: 10.1590/ So034-75902010000100002

Perrow, C. (1976), Análise organizacional: Um enfoque sociológico. São Paulo, SP: Atlas.

Pesqueux, Y. (2008).Filosofia e Organizações - Coleção Debates em Administração. Rio de Janeiro, RJ: Cengage.

Pinot de Villechenon, F. (2003). La latinidad: una cuestión de afinidad cultural en las relaciones euro-latinoamericanas. In Cavallero, P, A., Buzón, R, P., Frenkel, D., \& Nocito, A. Koronis. Homenaje a Carlos A. Ronchi March. Buenos Aires, Argentina: Universidad de Buenos Aires, p. 395-409

Pinot de Villechenon, F. P., Chanlat, J.-F., \& Rizzo, H. L. (2021). Dans quelle mesure la perception de proximité culturelle s'ajuste-telle au contact avec le marché cible? Les enseignements d'une recherche menée auprès de dirigeants de PME sud-européennes au Brésil. Management International, 25(6) (sous presse).

Rambaud, A., Richard, J. (2021). Philosophie d'une écologie anticapitaliste: Pour un nouveau modèle de gestion écologique. Ste-Foy, Québec, Canada: Les Presses de l'Université Laval, Paris, France: Hermann.

Ramirez Martinez, G., \& Gonzáles-Miranda, D, R. (2018). Tratado de estudios organizacionales. Volumen 1. Teorización sobre el campo, Medellin, Columbia. Editorial EAFIT, Universidad Autónoma Metropolitana, Red Mexicana de Investigadores en Estudios Organizacionales, Sage

Ramos, A. G. (1981/1989). A nova ciência das organizações: Uma reconceituação da Riqueza das Nações ( $2^{\mathrm{a}}$ ed.). Rio de Janeiro, RJ: Editora da FGV.

Ramos, G. (1983). Administração e contexto brasileiro: Esboço de uma teoria geral da administração ( $2^{\mathrm{a}}$ ed.). Rio de Janeiro, RJ: Editora da Fundação Getulio Vargas.

Ramos, G. (1984). Modelos de Homen e teoria administrativa. Revista de Administração Pública, 18(2), 3-12. Recuperado de http://bibliotecadigital.fgv.br/ojs/index.php/rap/article/ view/10559

Reynaud, J.-D. (1989). Les règles du jeu: l'Action collective et la régulation sociale. Paris, France: Armand Colin.

Richebé, N., Favereau, O., Livian, Y., Bréchet, J.-P., Taskin, L., Havard, C., \& Croset, N. (2020). La théorie de la régulation sociale: Hommage à Jean-Daniel Reynaud. Revue française de gestion, 6(6), 105-128. doi: 10.3166/rfg.2020.00437
Rossi, A., \& Passos, E. (2014). Análise institucional: Revisão conceitual e nuances da pesquisa-intervenção no Brasil. Revista EPOS, 5(1), 156-181.

Rouanet, S. P. (2010). Quelques remarques sur l'influence de la philosophie française au Brésil. Synergies, Brésil numéro spécial (2), 41-46. Recuperado de https://gerflint.fr/Base/ Bresil_special2/Rouanet.pdf

Rouquié A. (1987). Amérique latine: introduction à l'Extrême Occident. Paris, France: Seuil,

Sainsaulieu, R. (1977/2014). L'Identité au travail. Paris, France: Presses de la Fondation des Sciences Politiques.

Sainsaulieu, R. (Dir.). (1990). L'entreprise: Une affaire de société. Paris, France: Presses de la Fondation des Sciences Politiques.

Sainsaulieu, R. (1997). Sociologie de l'entreprise. Paris, France: Presses de la Fondation des Sciences Politiques.

Sainsaulieu, R. (2002). Des sociétés en mouvement. Paris, France: Desclée de Brouwer.

Sainsaulieu, R., \& Kirschner, A-M. (2006). Sociologia da Empresa Organização Poder, Cultura e Desenvolvimento no Brasil. Rio, Brasil: DP \& A Editora.

Sainsaulieu, R.,\& Segrestin, D. (1986, Juillet-septembre). Vers une théorie sociologique de l'entreprise. In: Sociologie du travail, 280 année, (3), pp. 335-352, Retour sur l'entreprise.

Salais, R., Thévenot, L.(éd.).(1986). Le travail : marché, règles et conventions. Paris, France: Economica.

Saussois, J. M. (2016). Les Organisations: Etat des savoirs, Paris, Editions Sciences Humaines.

Salvador, P. (2011, janeiro). Entrevista com Norbert Alter. Pequenas Empresas \& Grandes Negócios, 264. Recuperado de http:// revistapegn.globo.com/Revista/Common/o,,EMl19991517172,00-ENTREVISTA+COM+NORBERT+ALTER+INTEGRA.html

Sciences Humaines, (1998, Mars-Avril). Comprendre les organisations, 20. Recuperado de https://www. scienceshumaines.com/comprendre-les-organisations_fr_95. htm

Segnini, L., \& Alcadipani, R. (2014, maio/junho). Poder e resistências nas organizações: A propósito das contribuições de Fernando C. Prestes Motta. RAE-Revista de Administração de Empresas, 54(3), 341-347. doi: 10.1590/s0034$759020140309 \mathrm{~V}$

Segrestin, B.(1992). Sociologie de l'entreprise. Paris, France: Armand Colin.

Segrestin, B., \& Hatchuel, A. (2012). Refonder l'entreprise. Paris, France: Seuil.

Séguin, F.,\& Chanlat, J-F. (1983). L'analyse des organisations: une anthologie sociologique. Tome I. Montréal, Québec, Canada, Gaëtan Morin.

Serva, M. (1990). Contribuições para uma teoria organizacional brasileira. Revista de Administração Pública, 24(2), 10-21. Recuperado de http://bibliotecadigital.fgv.br/ojs/index. $\mathrm{php/rap/article/view/9047}$ 
Serva, M. (1992). A importação de metodologias administrativas no Brasil: uma análise semiológica. Revista de Administração Pública, 26(4), 128-144. Recuperado de http:// bibliotecadigital.fgv.br/ojs/index.php/rap/article/view/8751

Serva, M. (1997a). A racionalidade substantiva demonstrada na prática administrativa. RAE-Revista de Administração de Empresas, 37(2), 18-30. doi: 10.1590/s003475901997000200003

Serva, M. (1997b). Abordagem substantiva e ação comunicativa: Uma complementaridade frutuosa para a teoria das organizações. Revista de Administração Pública, 31(2), 108 134. Recuperado de http://bibliotecadigital.fgv.br/ojs/index. $\mathrm{php} / \mathrm{rap} /$ article/view/7940

Serva, M. (2002). Contribuições da sociologia econômica à teoria das organizações. Sociedade e Estado, 17(1), 106-122. doi: $10.1590 /$ s0102-69922002000100007

Serva, M. (2013). O surgimento e desenvolvimento da epistemologia da administração: Inferências sobre a contribuição ao aperfeiçoamento da teoria administrativa. RGO Revista Gestão Organizacional, 6(Edição especial), 51-64. doi: $10.22277 /$ rgo.v6i3.1529

Serva, M. (2017a). Epistemología de la administración en Brasil: El estado del arte. Cadernos EBAPE.BR, 15(4), 741-750. doi: 10.1590/1679-395173209

Serva, M. (2017b). A nova ideologia econômica da ciência e a (re) politização do campo. Ciências em Debate, 2, 52-58.

Serva, M., \& Andion, M.-C. (2006). Teoria das organizações e a nova sociologia econômica: Um diálogo interdisciplinar. RAERevista de Administração de Empresas, 46(2), 10-20. doi: 10.1590/S0034-75902006000200002

Serva, M., \& Andion, M.-C. (2021). La contribution de l'oeuvre de Jean-François Chanlat au champ des études épistémologiques des sciences administratives brésiliennes. In G. Bouville, \& H. Yousfi, Les dimensions oubliées de la gestion. Anthropologie, management et organisation: Mélanges en l'honneur de JeanFrançois Chanlat. Ste-Foy, Québec, Canada, Les Presses de l'université Laval, Paris, France: Hermann (à paraître).

Serva, M., Caitano, D., Santos, L., \& Siqueira, G. (2015). A análise da racionalidade nas organizações: Um balanço do desenvolvimento de um campo de estudos no Brasil. Cadernos EBAPE.br, 13(3), 414-437. Recuperado de http:// bibliotecadigital.fgv.br/ojs/index.php/cadernosebape/ article/view/16344

Silva, J.-R. G. da. (2010). La dynamique identitaire entre organisations et individus. Revue Française de Gestion, 36(20), 185-204. doi: 10.3166/rfg.203.185-204

Siqueira, G., \& Serva, M. (2014, março). Tensão entre racionalidades na abordagem substantiva das organizações. IV Colóquio Internacional de Epistemologia e Sociologia da Ciência da Administração, Florianópolis, SC.

Sperb, M. P., \& Serva, M. (2018). Economia social e solidária, governança e turismo no âmbito do desenvolvimento territorial sustentável. Revista de Ciências da Administração, 20(50), 93-109. doi: 10.5007/2175-8077.2018v2on50p93
Stokes, P., Davoine., E \& Oiry, E. (Guest Editors), (2014). Special issue on organizations and organizing in a French context. International Journal of Organizational Analysis, 22(4), 1-3. doi: 10.1108/IJOA-08-2014-0794

Sznelwar, I. L. (2006). Alain Wisner: O desenvolvimento da ergonomia e do pensamento sobre o "trabalhar". Travailler, 1(15), 55-70. doi: 10.3917/trav.015.0055

Sznelwar, L. I., Uchida, S., \& Lancman, S. (2011). A subjetividade no trabalho em questão. Tempo Social, 23(1), 11-30. doi: $10.1590 /$ S0103-20702011000100002

Terssac, G. de. (Ed.). (2003). La théorie de la régulation sociale de Jean-Daniel Reynaud. Paris, France: La Decouverte.

Thévenet, M. (1992). Auditoría de la cultura empresarial. Madrid, España: Ediciones Díaz de Santos.

Tietze, S., \& Dicks, P. (2012, May). The victorious English language: Hegemonic practices in the management academy. Journal of Management Inquiry, 22(1), 122-134. doi: $10.1177 / 1056492612444316$

Tonelli, M. J. (2018). Revistas científicas em administração: 0 papel histórico da Revista de Administração de Empresas (RAE) na construção do campo acadêmico em administração no Brasil. Cadernos EBAPE.BR, 16(Edição Especial), 509-515. doi: $10.1590 / 1679-395173941$

Torres, O., \& Gonçalves, M. A. (1991). O indivíduo na organização: dimensões esquecidas. RAE-Revista de Administração de Empresas, 31(4), 107-108. doi: 10.1590/ So034-75901991000400011

Tourish, D., \& Willmott, H, C. (2015, February). In Defiance of Folly: Journal Rankings, mindless measures and the ABS Guide. Critical Perspectives of Accounting, 26, 37-46. doi: 10.1016/j.cpa.2014.02.004

Tragtenberg, M. (2005). Administração, poder e ideologia. São Paulo, SP: Unisep.

Tragtenberg, M. (2010). Burocracia e ideologia. São Paulo, SP: Unisep.

Tragtenberg, M. (2012). Teoria e ação libertárias. São Paulo, SP: Unisep.

Tsuda, Y. (2013). Speaking Against the Hegemony of English Problems, Ideologies and Solutions. In The Handbook of Critical Intercultural Communication, Nakayama, T., \& Halualani, R, T, London, UK: Basil Blackwell, 248-269.

Tyr, A. (2007). Le drapeau brésilien et Auguste Comte [Film documentaire, coproduction Évasion en vidéo, PDR, TVM Est Parisien].

Vasconcelos, I., \& Pinochet, L. (2004). Poder, tecnologia e controle burocrático: Uma análise crozieriana em uma empresa de informática do governo do estado do Paraná. Revista de Administração Pública, 38(3), 465-479. Recuperado de http:// bibliotecadigital.fgv.br/ojs/index.php/rap/article/view/6546

Vergara, S. C. (2006). Análise organizacional no Brasil: Em busca da independência intelectual. In J.-F. Chanlat, R. Fachin, \& T. Fischer, Análise organizacional: Perspectivas latinas (Vol. 1: Olhar histórico e constatações atuais, pp. 219-238). Porto Alegre, RS: Editora da UFRGS. 
Vergara, S. C., \& Pinto, M. (2001). Referências teóricas em análise organizacional: Um estudo da nacionalidade dos artigos referenciados na literatura brasileira. Revista de Administração Contemporânea, 5(Edição Especial), 103-121. doi: $10.1590 /$ S1415-65552001000500006

Waiandt, C. A. (2009). O ensino dos estudos organizacionais nos cursos de pós-graduação stricto sensu em administração (Tese de doutorado, Escola de Administração, Universidade Federal da Bahia, Salvador, BA).
Waiandt, C. A. (2018). Ensino-Aprendizagem na administração: Contribuições e desafios na trajetória de Tânia Fischer. Farol - Revista de Estudos Organizacionais e Sociedade, 5(12), 85125. doi: $10.25113 /$ farol.v5i12.4797

Willmott, H. (2011). Journal List Fetishism and the Perversion of Scholarship: Reactivity and the ABS List. Organization, 18(4), 429-442.

\section{CONTRIBUIÇÃO DO ARTIGO}

O autor declara sua honra em, ele próprio, ter realizado este trabalho, da conceituação à abordagem teórica e metodológica até a versão final. 